Western University

Scholarship@Western

\title{
Spectral properties of lunar impact melt deposits from Moon Mineralogy Mapper (M3) data
}

\author{
Catherine Neish \\ cneish@uwo.ca \\ Kevin Cannon \\ Colorado School of Mines \\ Livio Tornabene \\ Western University \\ Roberta Flemming \\ Western University \\ Michael Zanetti \\ NASA Marshall Space Flight Center
}

See next page for additional authors

Follow this and additional works at: https://ir.lib.uwo.ca/earthpub

Part of the Earth Sciences Commons, and the The Sun and the Solar System Commons

\section{Citation of this paper:}

Neish, Catherine; Cannon, Kevin; Tornabene, Livio; Flemming, Roberta; Zanetti, Michael; and Pilles, Eric, "Spectral properties of lunar impact melt deposits from Moon Mineralogy Mapper (M3) data" (2021).

Earth Sciences Publications. 36.

https://ir.lib.uwo.ca/earthpub/36 
Authors

Catherine Neish, Kevin Cannon, Livio Tornabene, Roberta Flemming, Michael Zanetti, and Eric Pilles 
1 Spectral properties of lunar impact melt deposits from Moon Mineralogy Mapper $\left(\mathbf{M}^{3}\right)$ data

3

4 C.D. Neish ${ }^{1,2}$, K.M. Cannon ${ }^{3}$, L.L. Tornabene ${ }^{1,2}$, R.L. Flemming ${ }^{1,2}$, M. Zanetti ${ }^{4}$, 5

E. Pilles ${ }^{1,2}$

6

$7{ }^{1}$ Department of Earth Sciences, The University of Western Ontario, London, ON,

$8 \quad$ N6A 5B7 (cneish@uwo.ca)

$9 \quad{ }^{2}$ Institute for Earth and Space Exploration, The University of Western Ontario,

10 London, ON, N6A 5B7

$11{ }^{3}$ Department of Geology and Geological Engineering, Colorado School of Mines,

12 Golden, $\mathrm{CO}, 80401$

$13 \quad{ }^{4}$ NASA Marshall Space Flight Center, Huntsville, AL, 35808

14

Paper accepted in Icarus

16

17

February 5, 2021

18 


\section{Abstract}

21 Lunar impact melt deposits have unusual surface properties, unlike any measured

22 terrestrial lava flow. Radar observations suggest that they are incredibly rough at

23 decimeter scales, but they appear smooth in high-resolution, meter-scale optical

24 images. The cause of their unusual surface roughness is unknown. In this work,

25 we investigate the properties of impact melt deposits from seven lunar craters,

26 ranging in size from 7.5 to $96 \mathrm{~km}$ in diameter, in an effort to understand the cause

27 of their unique surface texture. We use data from the Lunar Reconnaissance

28 Orbiter's (LRO) Mini-RF instrument to characterize the small-scale roughness of

29 the deposits, data from the LRO Camera (LROC) to characterize their meter-scale

30 morphology, and data from Chandrayaan-1's Moon Mineralogy Mapper $\left(\mathrm{M}^{3}\right)$ to

31 characterize their composition. This represents the most comprehensive study of

32 the composition of lunar melt deposits completed to date. In particular, we applied

33 a customized spectral unmixing model to the $\mathrm{M}^{3}$ data using laboratory spectra

34 acquired from a range of possible lunar endmembers: pyroxene, olivine, fast-

35 quenched lunar glass simulants, and impact melts and breccias (both synthetic and

36 natural). We found that spectra derived from lunar melt deposits are typically

37 modeled as a mix of the pyroxene and/or impact melts and breccias endmembers.

38 Our modeled results suggest that lunar melt deposits are either crystalline deposits

39 of pyroxene-rich rocks, or a mixture of glassy material and pyroxene minerals.

40 The latter interpretation could explain the roughness observed in the Mini-RF

41 data, if the melt deposits have a glassy surficial layer that shatters during impact

42 gardening to produce decimeter scale blocks.

44 Key Words: Impact processes; Cratering; Moon; Moon, surface 


\section{Introduction}

Deposits of smooth, low albedo material are observed around many fresh

49 impact craters on the Moon [Howard and Wilshire, 1975; Hawke and Head, 1977;

50 Bray et al., 2010; Neish et al., 2014; Stopar et al., 2014]. These deposits have

51 been interpreted to be solidified melt from the impact event, ejected during the

52 late stages of impact crater formation [Hawke and Head, 1977; Osinski et al.,

53 2011]. Different forms of the deposits have been observed, including ponds,

54 veneers, and flows. In many cases, the morphologies of lunar impact melt flows

55 appear very similar to the morphologies of lava flows [e.g., Bray et al., 2010;

56 Denevi et al., 2012].

57 Despite their resemblance to lava flows in optical images, lunar impact

58 melt deposits have a surface texture unlike any known terrestrial lava flow [Neish

59 et al., 2017]. They are incredibly rough at decimeter scales, with radar returns at

60 S-Band $(12.6 \mathrm{~cm})$ similar to blocky lava flows on Earth [Campbell et al., 2010;

61 Carter et al., 2012; Neish et al., 2014; Neish et al., 2017]. However, in high-

62 resolution optical images ( $\sim 1 \mathrm{~m}$ scale), they appear quite smooth, more similar to

63 pahoehoe flows than blocky flows (Figure 1) [Bray et al., 2010; Neish et al.,

64 2017]. The reason for the unusual surface roughness of these flows is unknown.

65 One explanation is that the unique properties of lunar impact melt deposits

66 relate to the thermal conditions under which they formed. The surface texture of 
67 basaltic lavas, for example, are known to be strongly influenced by the efficiency 68 of surface cooling [Keszthelyi and Denlinger, 1996]. The cooling conditions of

69 lunar impact melt deposits differ markedly from terrestrial lava flows, which may 70 explain the observed differences in their surface roughness. Lunar impact melt 71 deposits cool under vacuum with initial temperatures often far in excess of their 72 liquidus [Simonds et al., 1976; Timms et al., 2017], while terrestrial lava flows 73 cool under a convective atmosphere with initial temperatures just above their

74 liquidus. Lunar impact melts also incorporate clasts of broken rock from the 75 impact event, which further alter their cooling conditions compared to terrestrial 76 lava flows, and are composed of whole rock melt, rather than a partial melt 77 [Osinski et al., 2018].

78 At the decimeter scale (S-Band, $12.6 \mathrm{~cm}$ ), impact melt deposits on

79 Mercury show similar surface textures to those on the Moon in radar data [Neish 80 et al., 2013], while impact melt flows on Venus do not [Dong et al., 2015]. No

81 impact melts have been studied on Mars using radar data, but the lava flows there 82 are often exceptionally rough at the decimeter scale [Harmon et al., 2012]. Young 83 lava flows on the Moon, in contrast, are often smooth at the decimeter scale

84 [Neish et al., 2017], although some older mare deposits have increased radar 85 backscatter at this scale [Campbell et al., 2009]. We thus posit that the unique 86 cooling conditions experienced by lunar impact deposits (initially superheated, 87 clast-choked, whole rock melt cooling under vacuum) may produce different 
88 surface textures than those experienced by lava flows, or impact melts on worlds

89 with thick, convective atmospheres.

90 In this work, we seek to characterize the physical and chemical properties

91 of lunar impact melts in an effort to better understand the origin of their unusual

92 surface texture. We use data from the Lunar Reconnaissance Orbiter's (LRO)

93 Mini-RF instrument [Nozette et al., 2010] to characterize the decimeter-scale

94 texture of the deposits, data from the LRO Narrow Angle Camera (LROC NAC)

95 to characterize their meter-scale morphology [Robinson et al., 2010], and data

96 from Chandrayaan-1's Moon Mineralogy Mapper $\left(\mathrm{M}^{3}\right)$ [Pieters et al., 2009] to

97 characterize their composition. In particular, we look for evidence in the $\mathrm{M}^{3}$ data

98 for spectral signatures that are consistent with one of four lunar endmembers:

99 pyroxenes (EM1), olivines (EM2), fast-quenched lunar glass simulants (EM3),

100 and impact melts and breccias (both synthetic and natural) (EM4). We use

101 laboratory spectra of these end members as inputs for the spectral unmixing

102 model described in Cannon et al. [2017].

103 One hypothesis that we seek to test is whether the unique cooling

104 conditions experienced by lunar impact melt deposits cause them to form with a

105 glassy surficial layer. Glasses are typically more brittle than polycrystalline rocks,

106 which means they will suddenly fail by breaking into smaller pieces with no

107 deformation [Altindag, 2010]. Rocks with higher mechanical strength are more

108 brittle than those with low mechanical strength, and obsidian has a compressive 
109 strength twice that of basalt [Fullagar and Torrence, 1991, Kahraman et al.,

110 2018]. We thus speculate that a glass-rich layer on a lunar melt deposit will be

111 disrupted after formation to produce decimeter sized blocks covering an otherwise

112 'smooth' flow, similar to experiments conducted with melted basalt at the

113 Syracuse University Lava Project (Figure 2). These experiments - which heat 800

114 pounds of crushed Wisconsin basalt to $1200^{\circ} \mathrm{C}$ for several hours - typically

115 produce smooth, glassy lava flows [Karson and Wysocki, 2012]. On the Moon,

116 impact melt deposits may be disrupted as a consequence of small impacts

117 breaking apart the surface crust [Ashworth, 1978], or the result of the explosive

118 degassing of volatiles trapped in the melt during cooling of the impact melt

119 deposit [Zanetti et al., 2011]. Note that radar has a penetration depth of up to 10

120 times the illuminating wavelength on the Moon [Neish et al., 2011], so these

121 blocks could be buried by up to a meter of regolith.

122 Evidence of glass in impact melt deposits is found in both returned

123 samples and remote sensing data of the lunar surface. Lunar impact melt breccias

124 often show a mixture of both crystalline and glassy material [e.g., Daubar et al.,

125 2002, Tompkins and Pieters, 2010], and there are rare examples of glassy impact

126 melt rocks in the Apollo collection [Osinski et al., 2018]. For example, sample

12764455 from the Apollo 16 collection is an egg-shaped object almost completely

128 covered with black glass [Ryder and Norman, 1980]. Spectral evidence for glass

129 in and around lunar impact craters has also been noted in a number of previous 
130 studies [Smrekar and Pieters, 1985; Mustard et al., 2011; Dhingra et al., 2013;

131 Horgan et al., 2014]. This evidence of glass is bolstered by the identification of

132 volcanic glasses using similar data sets and methods [e.g., Besse et al., 2014;

133 Cannon et al., 2017]. However, no comprehensive survey of the spectral

134 properties of melt-bearing craters has yet been undertaken. We aim to complete

135 such a survey in this work.

136

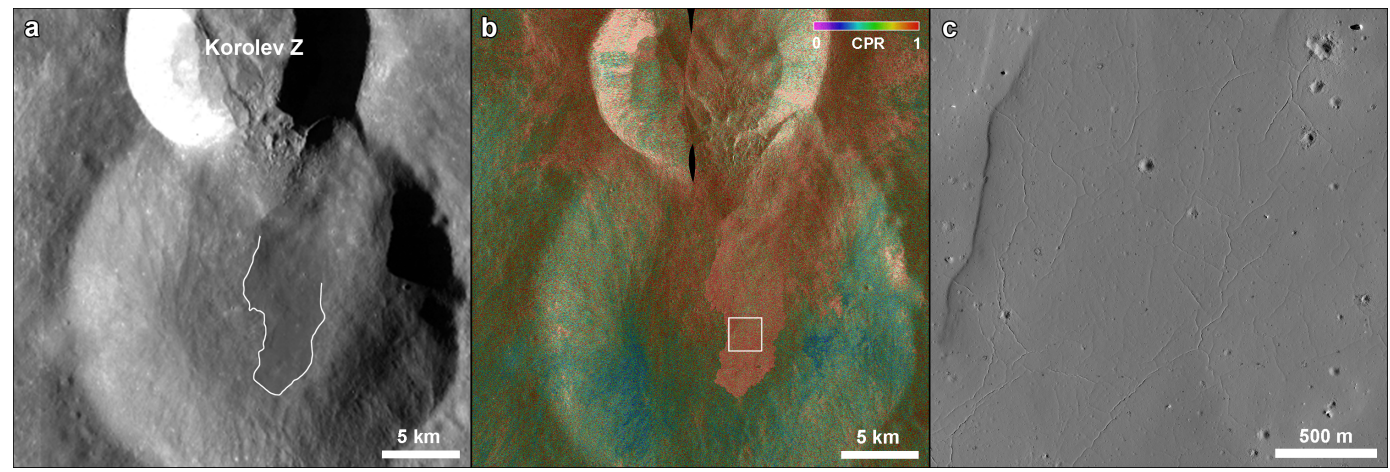

138 Figure 1: (a) A large melt deposit, outlined in white, is observed to flow out of 139 the southern rim of Korolev Z in this LROC WAC mosaic. (b) The Mini-RF data 140 indicate that this flow is blocky at the decimeter scale, yet a (c) close-up view of 141 the melt flow and roughness analyses conducted by Neish et al. [2017] suggest it 142 is smooth at the meter scale (LROC image M145671603RE.IMG). The location 143 of (c) is shown by a white box in (b). 


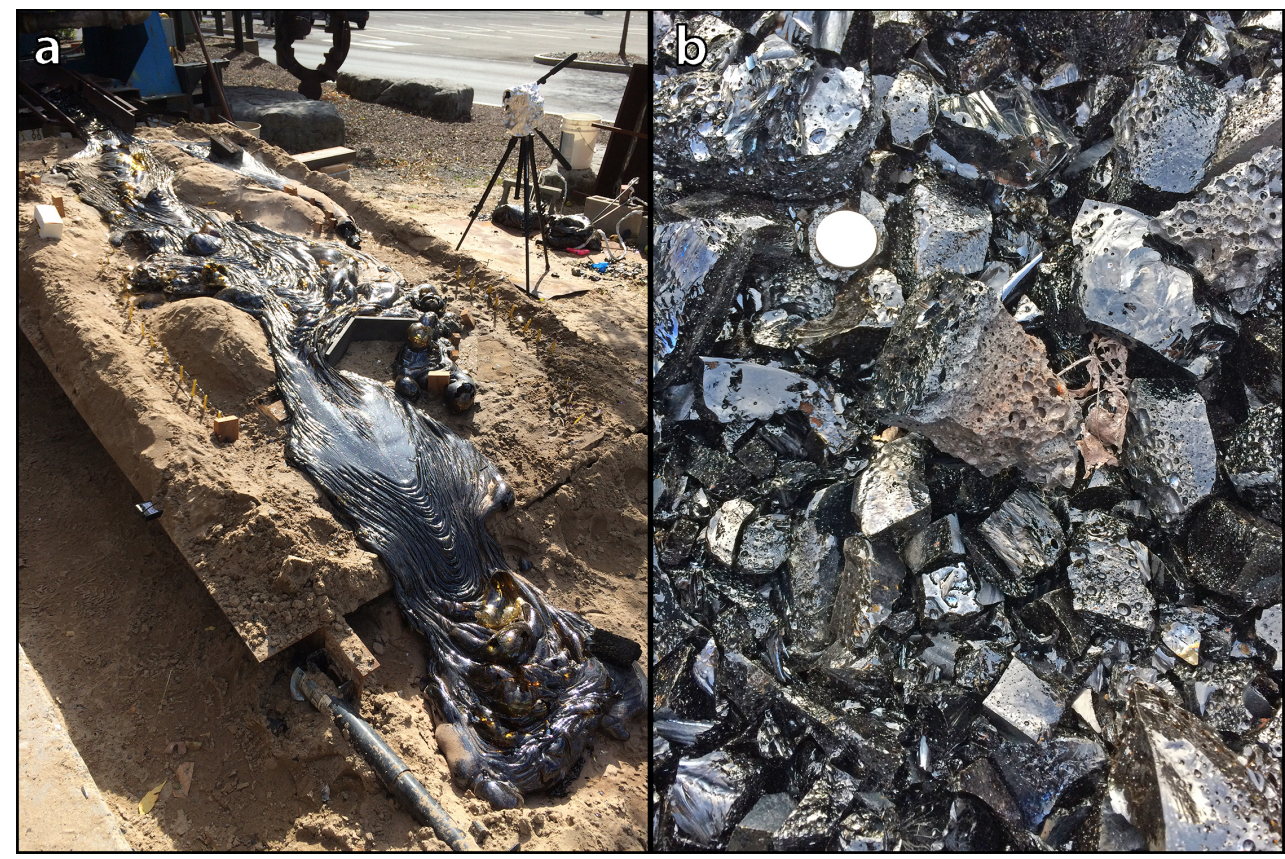

146 Figure 2: (a) A smooth but glassy flow produced at the Syracuse University Lava 147 Project (http://lavaproject.syr.edu) by pouring melted basalt over sand under the 148 terrestrial atmosphere. (b) When later broken apart, the flow fragments into 149 centimeter- to decimeter-sized blocks with sharp edges. A quarter is seen at top 150 left for scale. Image credit: Catherine Neish.

\section{2. Methods}

\subsection{Laboratory spectra}

Laboratory spectra of both synthetic and natural lunar materials were

157 acquired for comparison to spectra of impact melt deposits on the Moon. The

158 synthetic samples were of two different compositions: highlands-like and mare-

159 like. They were melted, then quenched in two different ways for a total of four 
160 samples (Figure 3). The materials were synthesized from raw oxide and carbonate

161 powders using the same methods described in detail by Cannon et al. [2017], one

162 with an average lunar highlands composition and one an average mare

163 composition [Taylor and McLennan, 2009]. The resultant spectra were obtained at

164 the Reflectance Experiment Laboratory (RELAB) facility (drop-quenched), and

165 using an ASD FieldSpec Spectrophotometer (slow-quenched).

166 As described in Cannon et al. [2017], drop-quenched samples were

167 measured with the custom-built UV-VIS-NIR bidirectional reflectance

168 spectrometer in the NASA RELAB facility at Brown University [Pieters, 1983].

169 The measured reflectance spectra cover $300-2550 \mathrm{~nm}$ with a sampling interval

170 of $10 \mathrm{~nm}$, and pressed halon was used as a white reference to achieve absolute

171 reflectance values. Incidence and emergence angles were 30 and 0 degrees,

172 respectively. Because the RELAB detector was undergoing extensive

173 maintenance at the time the experiments were conducted, we measured slow-

174 quenched VNIR spectra using an ASD FieldSpec Spectrophotometer.

175 Measurements were made using an ASD light source oriented at 30 degrees, and

176 the fiber optic oriented vertically above the sample (i.e., 0 degrees). Details about

177 the quenching procedures are given below.

178 First, we used spectra from a previous set of experiments [Cannon et al.,

179 2017] of pure quenched glass samples, which lacked any signs of crystallization

180 detectable to the unaided eye. These experiments used a platinum loop technique 
181 in a vertical $1 \mathrm{~atm}$ gas mixing furnace held at an oxygen fugacity $\left(f_{O 2}\right)$ of $1.5 \mathrm{log}$ 182 units below the iron-wüstite (IW) solid oxygen buffer, similar to lunar conditions

183 [Sutton et al., 2005]. Here, beads of melt were dropped from the hot spot of the

184 furnace into a beaker of water, cooling from above the liquidus to ambient 185 temperature in less than 1 second. These cooling rates are analogous to lunar 186 pyroclastic glasses [Hui et al., 2018], which are formed from fine droplets of melt 187 explosively launched into a vacuum. This method produced quenched glasses 188 with broad one and two micron bands, and these broad features are similar to but 189 distinguishable from crystalline pyroxene and/or olivine (based on their band 190 centers; see Table 1 and Figure 4). These spectra are similar to the re-melted 191 "prepared glass" spectra presented in Tompkins and Pieters [2010], which are 192 chemically equivalent to their Apollo 17 impact melt samples.

193 New to this study, two slow-cooled synthetic melts were also prepared.

194 We melted mixed powders (identical to the ones in the drop quench experiments) 195 in $2 \mathrm{ml}$ alumina crucibles in a horizontal $1 \mathrm{~atm}$ gas mixing furnace $\left(\log \left(f_{O 2}\right)=\right.$ -

196 1.5). Quenching was accomplished by shutting off the power to the furnace, such 197 that the melt cooled from above the liquidus to ambient temperatures at a 198 relatively fast rate (on the order of hours), but much slower than the quenched 199 melts described above. Throughout, we refer to these as "slow-cooled" or 200 "synthetic" melts, and they are somewhat analogous to the cooling conditions 201 experienced by a melt flow emplaced onto the lunar surface (although not under 
202 vacuum, nor of the volume expected for a melt flow). Upon visual inspection, this

203 form of quenching produced an opaque material with no clear signs of 204 crystallization for the mare composition, but showed clear evidence of

205 crystallization for the highlands composition (Figure 3). The spectral signature of 206 the highlands material at visible/near-infrared (VNIR) wavelengths shows broad

207 one- and two-micron absorption bands (the band centers are at $0.99 \mu \mathrm{m}$ and 2.19

$208 \mu \mathrm{m}$; see Table 1 and Figure 4), possibly from the presence of pyroxene. The slow-

209 cooled mare material is comparatively darker and has much lower spectral

210 contrast, with muted one and two micron absorption bands (with band centers at

$211 \quad 1.27 \mu \mathrm{m}$ and $1.95 \mu \mathrm{m})$.

212 To confirm the presence of crystallites in the slow quenched samples and 213 to determine their mineralogy, the highlands and mare samples were analyzed 214 using microXRD (X-ray diffraction). X-ray diffraction is a technique by which a

215 crystal lattice structure is inferred from the interaction of incident X-rays with the 216 sample, producing constructive interference when conditions satisfy Bragg's law

217 [Klug and Alexander, 1962]. The crushed, coarsely-crystalline samples were

218 mounted on an oriented quartz holder and placed on a Bruker D8 Discover micro

219 X-ray diffractometer using Co K $\alpha$ radiation $\left(\lambda_{\mathrm{Co} K \alpha 1}=1.78897 \AA\right)($ see Flemming 220 [2007] for geometry). They were then oscillated over $2 \mathrm{~mm}$ to allow the nominal 221300 -micron X-ray beam to sample more of the crystallites. Both samples showed 222 evidence for multiple crystalline minerals. An automated search using the 
223 International Centre for Diffraction Data (ICDD) PDF2 database revealed the 224 presence of plagioclase (anorthite) in both the highlands and mare samples, with 225 additional evidence for small amounts of olivine (forsterite) (Figure 5).

226 Clinopyroxene (augite) could also be present, however, its identification is not 227 definitive due to considerable peak overlap with anorthite (see Figure 5 and the 228 discussion below). In addition, an iron alloy was identified in the mare sample, as 229 well as a small amount of ilmenite.

230 Although the VNIR spectra of the slow quenched highlands melt strongly 231 suggests the presence of pyroxene, the XRD results suggest there is comparatively 232 little pyroxene in the sample. However, previous work has demonstrated that 233 small amounts of pyroxene (2-10\%) can dominate the VNIR spectral signature 234 when mixed with spectrally "bland" materials like glass or plagioclase [Tompkins 235 and Pieters, 2010; Cheek and Pieters, 2014]. Pyroxene should be detectable by 236 XRD down to $\sim 1 \%$ [Hill et al., 1993], using specialized methods like Rietveld 237 modal analysis. Unfortunately, our dataset was not amenable to Rietveld 238 refinement, so we performed conventional interpretation by visual inspection 239 using the ICDD database. This database cannot definitively identify low240 symmetry phases with modal proportion $<5 \%$ due to peak overlap [Klug and 241 Alexander, 1962]. Given the considerable peak overlap between the low242 symmetry phases anorthite (triclinic) and pyroxene (monoclinic), in addition to 243 olivine (orthorhombic), we estimate that there could be 5-10\% pyroxene present 
244 in this sample, as supported by VNIR data acquired of the same sample.

245 Finally, we used spectra of pure pyroxene and olivine samples from the 246 RELAB database, as well as spectra from actual Apollo impact melt and melt

247 breccia samples to compare to the spectra of impact melt deposits on the Moon 248 (Table 1). The Apollo samples that we used in this study are similar to other 249 impact melt and melt breccia samples for which spectra have been acquired 250 [Tompkins and Pieters, 2010]. This representative spectral library was used to 251 interpret the remote sensing data described in Section 2.2. These spectra are 252 unique from one another, allowing us to distinguish quenched glasses from pure 253 mafic minerals (pyroxene and olivine) as well as from materials with a mixture of 254 glass and crystals (synthetic slow-cooled melts, Apollo melts and melt breccias). 255 However, geologic context is necessary to properly interpret the results. For 256 example, quenched glasses are also found in pyroclastic deposits, while minerals 257 in partially crystallized and/or clast-bearing impact melts (pyroxene, olivine, 258 plagioclase) may be found in extrusive or intrusive igneous rocks.

259 All of the spectra used in this work were continuum removed using the 260 "Continuum Removal" function available in ENVI 5.5, over the wavelength range 261 of 0.5 to 2.5 microns. In short, the continuum is removed by dividing the original 262 spectrum by the continuum curve. The continuum curve is calculated by fitting a 263 convex hull over the top of the spectrum, using straight-line segments that 264 connect local maxima. Besse et al. [2011] found that the ENVI continuum 
265 removal has some limitations when applied to noisy spectra, and could possibly

266 shift the $\mathrm{M}^{3}$ band centers. However, when we implemented a manual continuum

267 removal for one representative spectrum, we found a shift in band position of only

$268 \quad 10-20 \mathrm{~nm}$. We have thus decided to utilize the ENVI continuum removal for this

269 work. We then calculated the band centers for each spectrum by fitting an $11^{\text {th }}$ -

270 order polynomial to the 1 and 2 micron bands, and determining the minimum of

271 the fit to the absorption band. For the glass spectra, we had to remove a linear

272 slope in the data before fitting the polynomial to the 2 micron band. The results

273 are presented in Table 1.

274

275

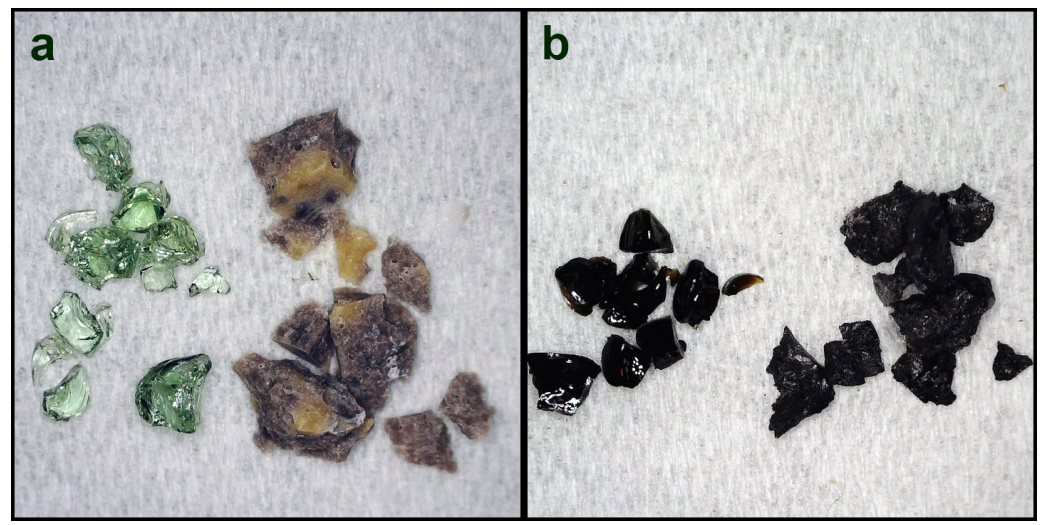

276 Figure 3: (a) Samples of melted highlands material that has been drop quenched

277 (left) compared to identical melt that has also been quenched, but more slowly

278 (right). (b) Samples of melted mare material that has been drop quenched (left)

279 compared to identical melt that has also been quenched, but cooled more slowly

280 (right). Although identical in composition, the differences in cooling rate produce

281 solid samples that are visually and spectrally distinct from one another. In

282 particular, the drop-quenched samples are distinctly more vitreous in luster,

283 indicating that they are glassier than the slow-quenched samples. 

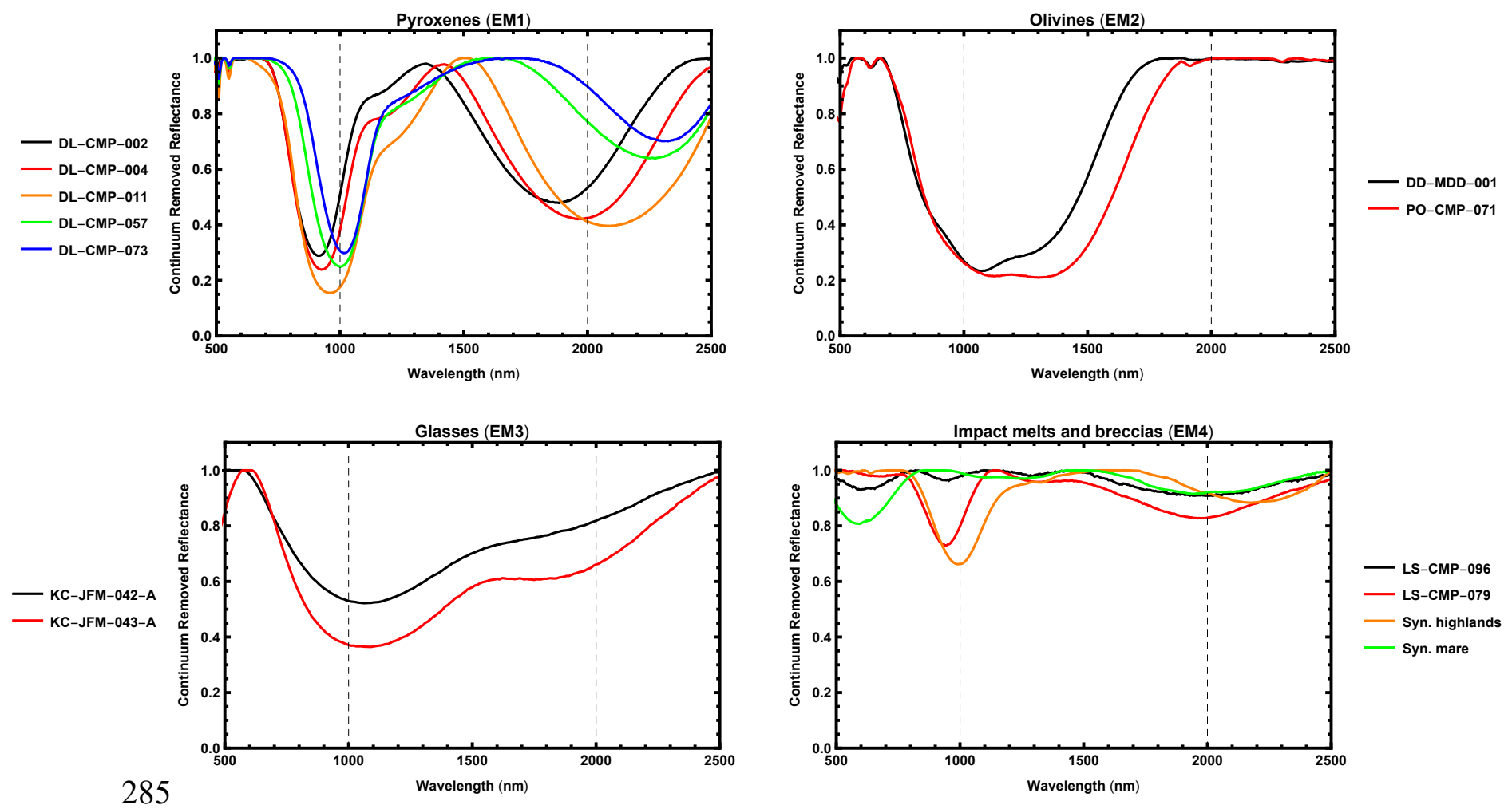

286 Figure 4: Continuum removed VNIR spectra of the four sets of lunar end members studied in this work: pyroxenes (EM1), olivines (EM2), fast-quenched

288 lunar glass simulants (EM3), and impact melts and breccias (both synthetic and 289 natural) (EM4). A description of each spectrum is given in Table 1. Note that the 290 fast-quenched glass samples are low contrast and show shallow, broad absorption 291 bands centered near one and two microns, while the slow-quenched, synthetic 292 highlands melt shows more distinct absorption bands, consistent with the presence 293 of crystalline pyroxene (it appears most similar to the synthetic clinopyroxene $294 \mathrm{Wo}_{25} \mathrm{En}_{36} \mathrm{Fs}_{39}$, DL-CMP-057). 

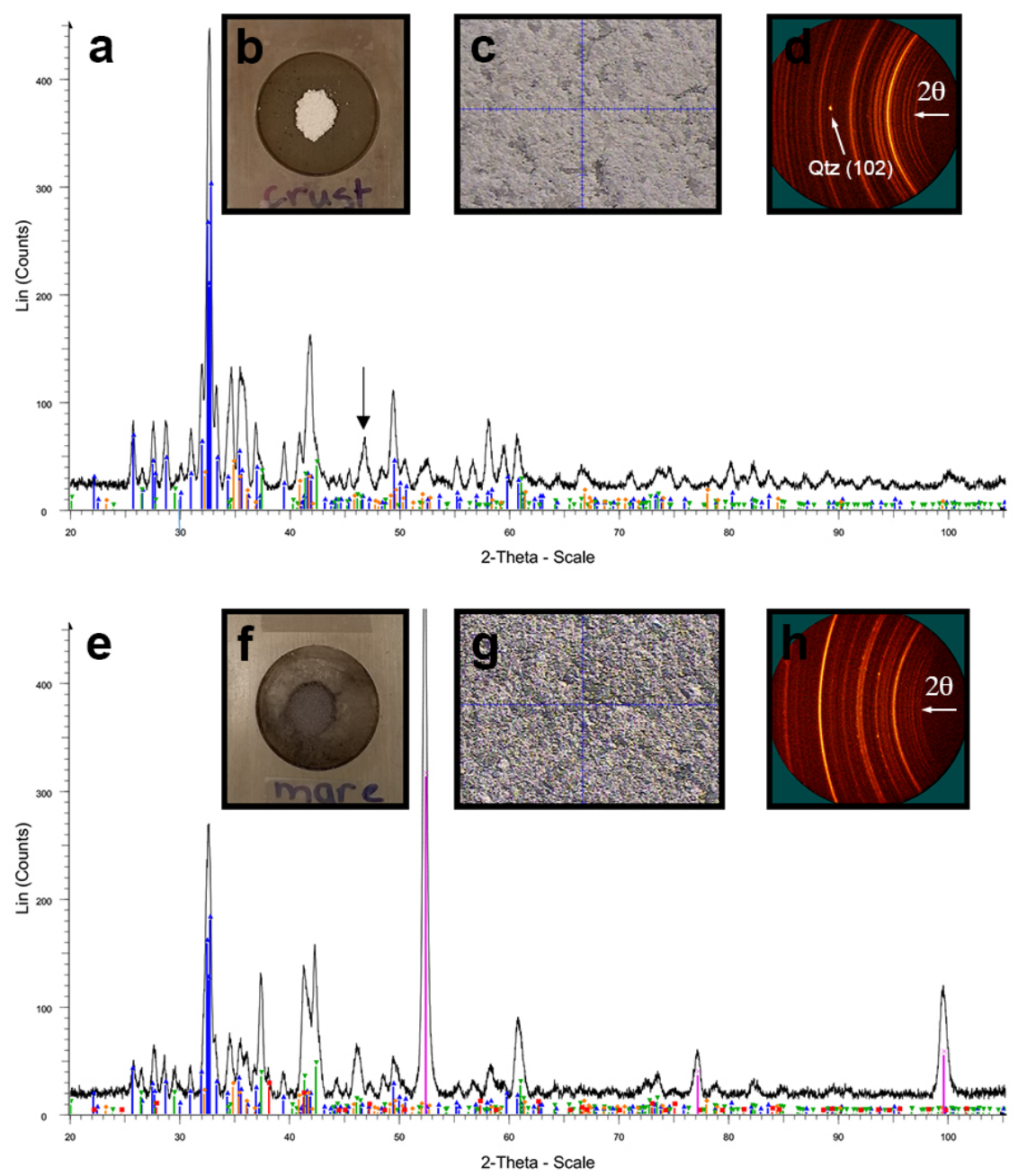

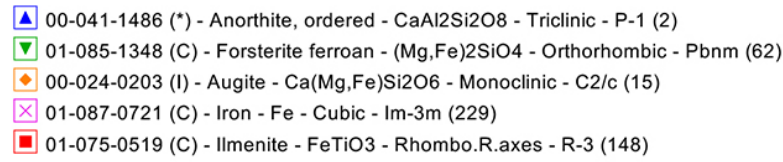

Figure 5: XRD results for the slow-quenched (a) highlands and (e) mare samples. Diffraction patterns show that anorthite (blue), forsterite (green), and clinopyroxene (orange) were identified in both samples. An iron alloy (pink) and ilmenite (red) were identified in the mare sample. (b and f) Highlands and mare samples are shown mounted on a one inch diameter oriented quartz sample holder. (c and g) Highland and mare target locations, as viewed through the microscope on the XRD (FOV $=2 \mathrm{~mm}$ ). Shards of glass can be seen in the highlands sample in image (c). A variety of colours and textures can be seen in image $(\mathrm{g})$, visibly indicating multiple phases. ( $\mathrm{d}$ and $\mathrm{f}$ ) Two-dimensional General 
Area Detector Diffraction System (GADDS) images for highlands and mare samples. Homogenous Debye rings in (d) indicate fine-grained material $(<5 \mu \mathrm{m})$.

308 Grainy or 'spotty' rings in (h) are indicative of some phases having courser grain sizes $(>10 \mu \mathrm{m})$. The bright spot in d (black arrow in a) is due to a signal from the

310 quartz sample holder. Instrumental parameters are as follows: coupled scan, two 311 frames $\left(\theta 1=\theta 2=20^{\circ}\right)$, width between frames $=45^{\circ}$, time $=2 \mathrm{hr} /$ frame. The 312 sample was oscillated $2 \mathrm{~mm}$ in XY during data collection. Each conventional intensity versus 2 -Theta diffraction pattern shown here has been derived by integration of two GADDS images, with subsequent background subtraction and phase identification using the ICDD PDF2 database.

Table 1: Description of spectra used for the four endmembers in the spectral unmixing model.

\begin{tabular}{lll}
\hline Pyroxenes (EM1) & RELAB ID & Band Centers $(\mu \mathrm{m})$ \\
\hline Synthetic orthopyroxene $\mathrm{Wo}_{0} \mathrm{En}_{80} \mathrm{Fs}_{20}$ & DL-CMP-002 & $0.91,1.88$ \\
Synthetic orthopyroxene $\mathrm{Wo}_{0} \mathrm{En}_{50} \mathrm{Fs}_{50}$ & DL-CMP-004 & $0.93,1.97$ \\
Synthetic pigeonite $\mathrm{Wo}_{14} \mathrm{En}_{36} \mathrm{Fs}_{50}$ & DL-CMP-011 & $0.96,2.09$ \\
Synthetic clinopyroxene $\mathrm{Wo}_{25} \mathrm{En}_{36} \mathrm{Fs}_{39}$ & DL-CMP-057 & $1.00,2.26$ \\
Synthetic clinopyroxene $\mathrm{Wo}_{39} \mathrm{En}_{36} \mathrm{Fs}_{25}$ & DL-CMP-073 & $1.02,2.31$ \\
\hline
\end{tabular}

\section{Olivines (EM2)}

Olivine from Chassigny $\mathrm{Fo}_{68} \quad$ DD-MDD-001 1.09 , N/A

$\begin{array}{lll}\text { St. Peter's Fayalite } & \text { PO-CMP-071 } & 1.29, \text { N/A }\end{array}$

Glasses (EM3)

Fast-quenched synthetic highlands $\quad$ KC-JFM-042-A $\mathrm{A}^{\mathrm{b}} \quad 1.07,1.98$ glass

Fast-quenched synthetic mare glass $\quad$ KC-JFM-043-A $\mathrm{A}^{\mathrm{b}} \quad 1.07,1.99$

Impact melts and breccias (EM4)

$\begin{array}{lll}\text { Slow-quenched synthetic highlands } & \mathrm{N} / \mathrm{A}^{\mathrm{c}} & 0.99,2.19\end{array}$

melt

Slow-quenched synthetic mare melt $\quad \mathrm{N} / \mathrm{A}^{\mathrm{c}} \quad 1.27,1.95$

Apollo 15 impact melt 15445,261 $\quad$ LS-CMP-096-D ${ }^{\mathrm{d}} \quad$ 0.94, 1.98

Apollo 17 impact melt breccia $\quad$ LS-CMP-079 ${ }^{\mathrm{d}} \quad 0.94,1.97$

76295,123

${ }^{c}$ These are new spectra acquired in this work. They are available in the Supplementary Material.

${ }^{\mathrm{d} D e s c r i b e d ~ b y ~ T o m p k i n s ~ a n d ~ P i e t e r s ~[2010] . ~}$ 
328 In this work, we used Moon Mineralogy Mapper $\left(\mathrm{M}^{3}\right)$ data to constrain the

329 mineralogy of seven representative lunar craters with deposits of impact melt

330 (Table 2). $\mathrm{M}^{3}$ was a hyperspectral imager that collected data from 540 to 2976

$331 \mathrm{~nm}$, with a spectral resolution of $40 \mathrm{~nm}$ and a spatial resolution of $140 \mathrm{~m} / \mathrm{pixel}$ in

332 the global imaging mode [Pieters et al., 2009]. For each crater, we identified one

333 or more $\mathrm{M}^{3}$ images with overlapping coverage of the crater. Where possible, we

334 selected images from Optical Period 1A, 1B, or 2A. During this period,

335 Chandrayaan-1 was in a lower orbit with a single star tracker intact; after this

336 period, Chandrayaan-1 was moved to a higher orbit (200 km vs. $100 \mathrm{~km})$ and had

337 no working star trackers [Green et al., 2011]. As a result, the spatial resolution

338 was reduced to $280 \mathrm{~m} /$ pixel in Optical Periods $2 \mathrm{~B}$ and 2C. In all cases, we used

339 the Level 2 reflectance (RFL) data for further analysis, and the corresponding

340 location (LOC) file for map projection. The Level 2 data have been thermally and

341 photometrically corrected as described in Clark et al. [2011] and Besse et al.

342 [2013], respectively. Although impact melts deposits are more common amongst

343 highlands craters [Neish et al., 2014; Stopar et al., 2014], craters were selected to

344 represent a mix of both highlands and mare target materials. All selected craters

345 display prominent impact melt deposits (i.e., ponds and flows) on their ejecta

346 blankets [Neish et al., 2014]. We also avoided craters north or south of $\sim 40^{\circ}$ 
347 latitude, as illumination geometry can influence the spectral parameter maps.

348 After cropping the $\mathrm{M}^{3}$ data to the region of interest, we applied the 349 spectral unmixing model developed by Cannon and Mustard [2015] and

350 described in detail by Cannon et al. [2017] to the data over the spectral range 620

351 to $2597 \mathrm{~nm}$. Briefly, this model uses linear unmixing in single-scattering albedo

352 space to represent a remote spectrum as a combination of laboratory and scene353 derived (i.e., from the $\mathrm{M}^{3}$ data itself) endmembers. The scene-derived 354 endmembers were extracted by using the average of the detector column for each

355 pixel. A statistical F-test is used to evaluate whether a particular endmember of 356 interest (for example, EM3, fast-quenched lunar glass simulants) is likely to be

357 present in the remote spectrum, or if the remote spectrum can be well-modeled by 358 crystalline minerals (pyroxene/olivine) and neutral components alone.

359 The model is run on the original spectra, which have not been continuum-

360 removed, and iteratively compares these endmembers to find which has the lowest

361 F value. If the endmembers don't improve the model fit with statistical

362 significance, they are not modeled. For example, if a spectral feature is ubiquitous

363 and part of the "background" of the entire scene, then the model may not pick it

364 out as being distinct because it uses spectra from the scene itself as an

365 endmember. The model reports the fraction of each spectrum used in the fit in the

366 raw output. However, we chose not to report this information in the present work,

367 as our goal is not to identify the presence of a specific mineral, but rather to see if 
368 we can distinguish melt deposits from mafic minerals. Instead, the results are

369 provided in a four-band image cube, where the individual bands are representative

370 of the input endmembers. These can be used to make RGB composite images to

371 provide a semi-quantitative representation of the different endmember mixtures

372 present at any point on the lunar surface.

373 The model is specifically designed to minimize false positive detections of

374 spectrally subtle materials like glasses, and does not attempt to derive absolute

375 physical abundances for the endmembers because of the highly non-unique

376 inversions involved. Nonetheless, any regions that are spectrally bland, with

377 broad but weak one and two micron bands, are difficult to confidently assign to an

378 endmember. Thus in some cases, there are false positive results where the spectral

379 model attempted to assign an endmember to a region that does not show distinct

380 spectral features. In previous work [Cannon et al., 2017], this model successfully

381 identified pyroclastic glass deposits in Alphonsus crater using $\mathrm{M}^{3}$ data (i.e., the

382 fractional abundance was greater than zero), and was able to show that signatures

383 of glass decreased radially away from the volcanic vents.

384 We then map projected the resulting model outputs for all localities listed

385 in Table 2, and georegistered them to images from the Lunar Reconnaissance

386 Orbiter (LRO) Wide Angle Camera (WAC) and Narrow Angle Camera (NAC), as

387 well as radar images from the Mini-RF radar on LRO and from the Arecibo

388 Observatory (both at S-Band, $12.6 \mathrm{~cm}$ ). Radar is sensitive to roughness at the 
389 scale of the radar wavelength [Neish and Carter, 2014], so these maps provide

390 information about the decimeter-scale roughness at the surface and near-

391 subsurface (up to $\sim 1 \mathrm{~m}$ in regolith). Using the optical and radar images, we

392 mapped out obvious regions of melt for comparison to the spectral unmixing

393 model. We produced two RGB composite images of the spectral unmixing results.

394 In the first, the total crystalline mafic endmembers (pyroxenes, EM1, plus

395 olivines, EM2) inferred from the model is represented by red, impact melts and

396 melt breccias (EM4) by green, and pure quenched glasses (EM3) by blue. In the

397 second, the total "impactite" content (fast-quenched lunar glass simulants, EM3,

398 and impact melts and breccias, EM4) inferred by the model is represented by red,

399 pyroxenes (EM1) by green, and olivines (EM2) by blue. We discuss each crater

400 separately in Section 3.

401 Table 2: Craters investigated in this work, with corresponding $\mathrm{M}^{3}$ data, in order 402 of size.

\begin{tabular}{|c|c|c|c|c|c|c|c|}
\hline Crater & $\begin{array}{c}\text { Diameter } \\
(\mathbf{k m})\end{array}$ & $\begin{array}{l}\text { Lat. } \\
\left({ }^{\circ} \mathbf{N}\right)\end{array}$ & $\begin{array}{l}\text { Lon. } \\
\left({ }^{\circ} \mathbf{E}\right)\end{array}$ & Location & $M^{3}$ Image(s) & $\begin{array}{c}\text { Spatial } \\
\text { Resolution }\end{array}$ & $\begin{array}{l}\text { Optical } \\
\text { Period }\end{array}$ \\
\hline Donner $\mathrm{M}$ & 7.5 & -32.2 & 97.9 & Highlands & $\begin{array}{l}\text { M3G20090601T062753_V01_ } \\
\text { RFL.IMG }\end{array}$ & 280 m/pixel & $2 \mathrm{C}$ \\
\hline Tharp & 13 & -30.9 & 145.5 & Highlands & $\begin{array}{l}\text { M3G20090528T130108_V01_ } \\
\text { RFL.IMG }\end{array}$ & $280 \mathrm{~m} /$ pixel & $2 \mathrm{C}$ \\
\hline $\begin{array}{l}\text { Giordano } \\
\text { Bruno }\end{array}$ & 22 & 35.9 & 102.8 & Highlands & $\begin{array}{l}\text { M3G20090531T215442_V01_ } \\
\text { RFL.IMG }\end{array}$ & $280 \mathrm{~m} /$ pixel & $2 \mathrm{C}$ \\
\hline Aristarchus & 42 & 23.7 & -47.3 & Mare & $\begin{array}{l}\text { M3G20090209T054031_V01_ } \\
\text { RFL.IMG } \\
\text { M3G20090209T072710_V01_ } \\
\text { RFL.IMG }\end{array}$ & $140 \mathrm{~m} /$ pixel & $1 \mathrm{~B}$ \\
\hline Glushko & 43 & 8.4 & -77.6 & $\begin{array}{l}\text { Highlands/ } \\
\text { mare border }\end{array}$ & $\begin{array}{l}\text { M3G20090614T131003_V01_ } \\
\text { RFL.IMG }\end{array}$ & $280 \mathrm{~m} /$ pixel & $2 \mathrm{C}$ \\
\hline King & 76 & 5.0 & 120.5 & Highlands & $\begin{array}{l}\text { M3G20081231T034148_V01_ } \\
\text { RFL.IMG }\end{array}$ & $140 \mathrm{~m} /$ pixel & $1 \mathrm{~A}$ \\
\hline Copernicus & 96 & 9.6 & -20.1 & Mare & $\begin{array}{l}\text { M3G20090207T044515_V01_ } \\
\text { RFL.IMG }\end{array}$ & $140 \mathrm{~m} /$ pixel & $1 \mathrm{~B}$ \\
\hline
\end{tabular}




\section{Results}

404

$405 \quad 3.1$ Donner $M$

406

407

Donner $\mathrm{M}$ is a $\sim 7.5 \mathrm{~km}$ diameter crater located on the southern rim of

408 Donner crater. A prominent, lobate flow is seen emerging from the northern rim

409 of Donner M crater onto the floor of the more ancient Donner crater. Cooling

410 cracks and leveed channels are observed in the LROC NAC images, indicative of

411 its origin as an impact melt deposit [Neish et al., 2014]. The melt flow has high

412 radar backscatter and circular polarization ratios in the Mini-RF data set, 413 suggesting a surface that is blocky at the decimeter scale.

414 When the spectral unmixing model is applied to the $\mathrm{M}^{3}$ data in this region,

415 the melt flow is mapped as a pyroxene deposit (Figure 6). The averaged spectrum 416 taken of this region shows the most similarities to the clinopyroxene spectrum 417 DL-CMP-011 given in Figure 7 (with band centers at 0.96 and $2.11 \mu \mathrm{m}$, 418 compared to 0.96 and $2.09 \mu \mathrm{m})$. In a large melt flow produced from a 419 predominately anorthositic target rock, we would expect pyroxene to form as part 420 of the crystallization sequence [Vaughan et al., 2013]. However, this does not 421 necessarily imply that the flow is a purely crystalline pyroxene exposure. Only a 422 small percentage of crystals are needed to show spectral evidence for pyroxene; 423 Tompkins and Pieters [2010] found that $>60 \%$ glass is necessary for the presence 
424 of glass to be obvious in a mixed spectrum. Furthermore, Cheek and Pieters

425 [2014] found that pyroxene is spectrally dominant at just 2 vol. \% abundance in

426 pyroxene-plagioclase mixtures. Therefore, even an intimate mixture dominated by

427 plagioclase and/or glass may still not be spectrally distinct from the pyroxene

428 endmember in our spectral unmixing model. (Note that the lunar highlands are

429 dominated by anorthosite, so we would expect a large fraction of the melt to be

430 plagioclase-rich [e.g., Wānke et al., 1975], even though it is readily masked by

431 other phases in the VNIR.)

432

433
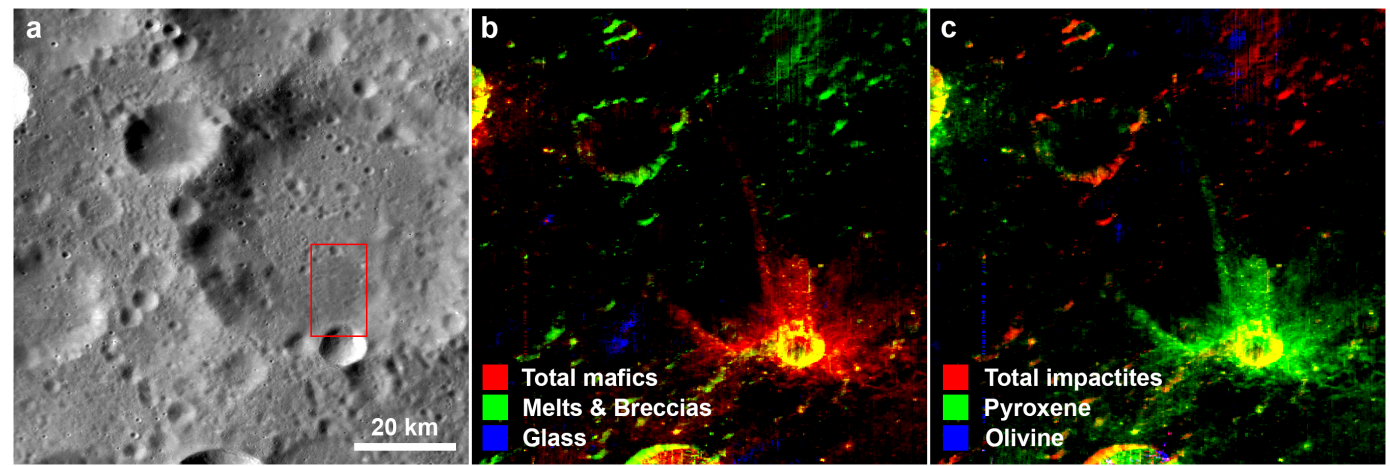

434 Figure 6: (a) LROC WAC mosaic of a small crater on the rim of Donner crater. 435 The red box indicates the location of Figure 7. (b) Spectral unmixing results from 436 the $\mathrm{M}^{3}$ image M3G20090601T062753_V01_RFL.IMG. Here, red represents the 437 combined mafic endmembers (pyroxenes, EM1, and olivines, EM2), green 438 represents impact melt and breccia endmembers (EM4), and blue represents 439 quenched glass endmembers (EM3). (c) Spectral unmixing results, where red 440 represents the combined impactite endmembers (quenched glass, EM3, and 441 impact melts and breccias, EM4), green represents pyroxene-rich endmembers 442 (EM1), and blue represents olivine-rich endmembers (EM2). The red and blue 443 bands in (b) and the green and blue bands in (c) have been scaled linearly from 4440.01 to their maximum value, to remove spuriously low values. The green band in 445 (b) and the red band in (c) have been scaled linearly from 0.1 to their maximum 446 value. 

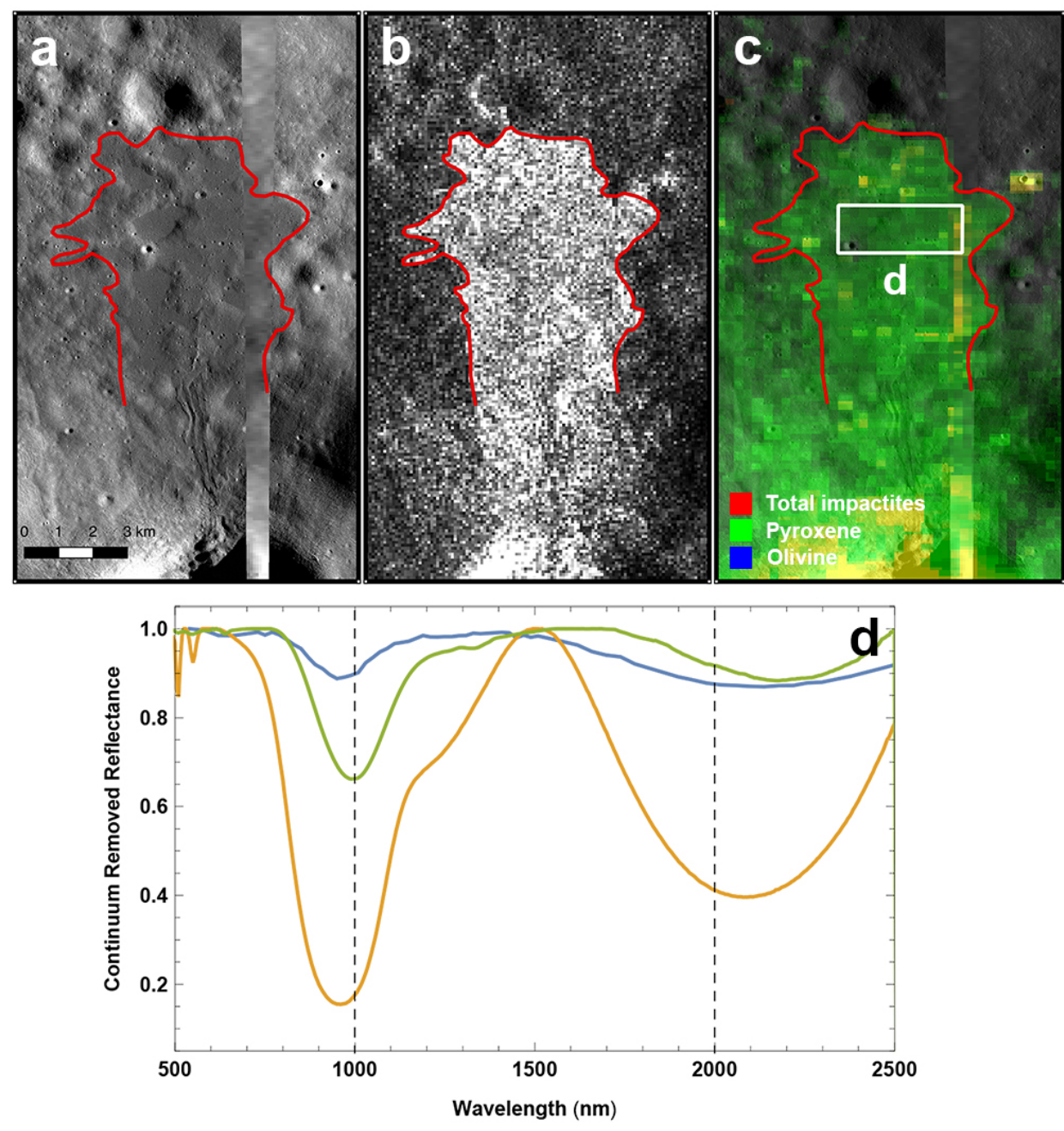

\section{— Donner Melt — Clinopyroxene - Highlands Slow Quench}

Figure 7: (a) LROC NAC mosaic of a prominent melt flow emanating from the lobate portion of the flow has been outlined in red. (b) Mini-RF total power image of the same region indicates the melt flow is rough at the decimeter scale (LSZ_04611_1CD_XKU_35S098_V1.IMG). (c) Spectral unmixing results of this region suggest the flow is spectrally consistent with the pyroxene endmember (EM1). A white box indicates the region where the spectrum shown in (d) was extracted. (d) Average continuum removed spectrum of a portion of the melt flow from Donner M, compared to a clinopyroxene spectrum (sample DL-CMP-011) and the highlands slow quench spectrum given in Figure 4. 
463 extensive downrange melt flows identified by Carter et al. [2012]. These deposits

464 are darker-toned with respect to their surroundings, consistent with other lunar

465 melts, and also exhibit cooling cracks and evidence of ponding in low-lying local

466 topography. Lobate margins, flow features, and possible evidence of inflation are

467 observed in one prominent melt flow observed west-northwest of the crater. This

468 melt has high radar backscatter in the Mini-RF data, indicating a surface that is

469 rough at the decimeter scale [Carter et al., 2012; Neish et al., 2014].

470 When the spectral unmixing model is applied to the $\mathrm{M}^{3}$ data in this region, 471 the Tharp ejecta blanket appears most consistent with a mixture of mafic 472 components and impact melts/breccias (Figure 8). Zooming in on an individual 473 melt deposit, we see that the model identifies the unit as being most consistent 474 with impact melts/breccias (Figure 9). An average spectrum of this region shows 475 evidence of pyroxene absorptions, similar to our slow-cooled synthetic highlands 476 melt. The band centers of the melt deposit are at 0.95 and $2.14 \mu \mathrm{m}$, compared to $477 \quad 0.99$ and $2.19 \mu \mathrm{m}$ for the slow-cooled synthetic highlands melt.

478 However, the melts/breccias spectral unit also appears elsewhere in the 479 unmixing model, in regions where there is no obvious melt. For example, there is 480 a strong signature just east of the crater, in a region of blocky ejecta (Figure 10). 
481 Here, the presence of non-pyroxene phases such as plagioclase may be 482 influencing the spectral model, producing spurious results (since plagioclase is 483 spectrally bland). In another nearby region, a melt veneer was classified as a 484 mafic exposure, with a pyroxene-like spectrum (Figure 10d). As in the case of 485 Donner M, the melt could be a mixture of spectrally featureless components such 486 as glass or plagioclase with small amounts of pyroxene. Both regions northeast of 487 the crater have spectra with nearly identical band centers, 0.94 and $2.11 \mu \mathrm{m}$ for 488 the ejecta and 0.95 and $2.11 \mu \mathrm{m}$ for the veneer.

489 The melts/breccias spectral unit also extends throughout much of the 490 northern portion of Figure 8, possibly the result of rayed ejecta emanating from 491 Tharp. Tharp has an obvious ray pattern in optical images, indicating impact was 492 from the southeast towards the northwest [Neish et al., 2014]. The crater rays are 493 consistent with the melts/breccia endmember, giving confidence that our model 494 can distinguish melt-rich ejected materials from other possible endmembers. 495 However, an average spectrum taken from this region is distinct from the melt 496 deposits, with muted spectral absorption bands, and a two micron band that is 497 offset from the melt spectra (Figure 11). The band centers in this region are found 498 at 0.91 and $2.19 \mu \mathrm{m}$, compared to 0.95 and $2.14 \mu \mathrm{m}$ for the melt deposits. These 499 are likely pyroxene signatures mixed with different minerals. 


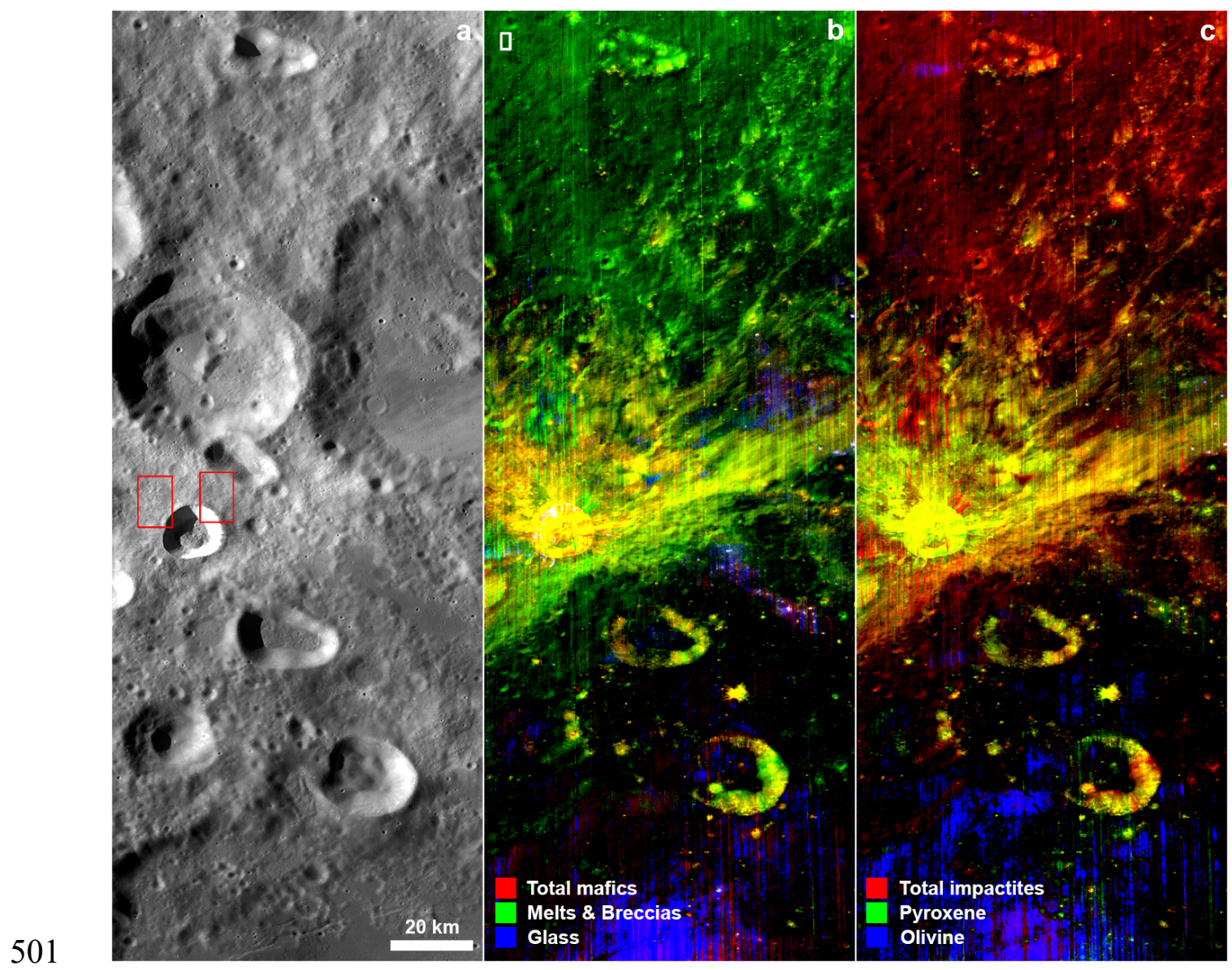

502 Figure 8: (a) LROC WAC mosaic of Tharp crater. The red boxes indicate the 503 location of Figures 9 and 10. (b) Spectral unmixing results from the $\mathrm{M}^{3}$ image 504 M3G20090528T130108_V01_RFL.IMG. Here, red represents the combined 505 mafic endmembers (pyroxenes, EM1, and olivines, EM2), green represents 506 impact melt and breccia endmembers (EM4), and blue represents quenched glass 507 endmembers (EM3). (c) Spectral unmixing results, where red represents the 508 combined impactite endmembers (quenched glass, EM3, and impact melts and 509 breccias, EM4), green represents pyroxene-rich endmembers (EM1), and blue 510 represents olivine-rich endmembers (EM2). All bands have been scaled linearly 511 from 0.01 to their maximum value, to remove spuriously low values. 

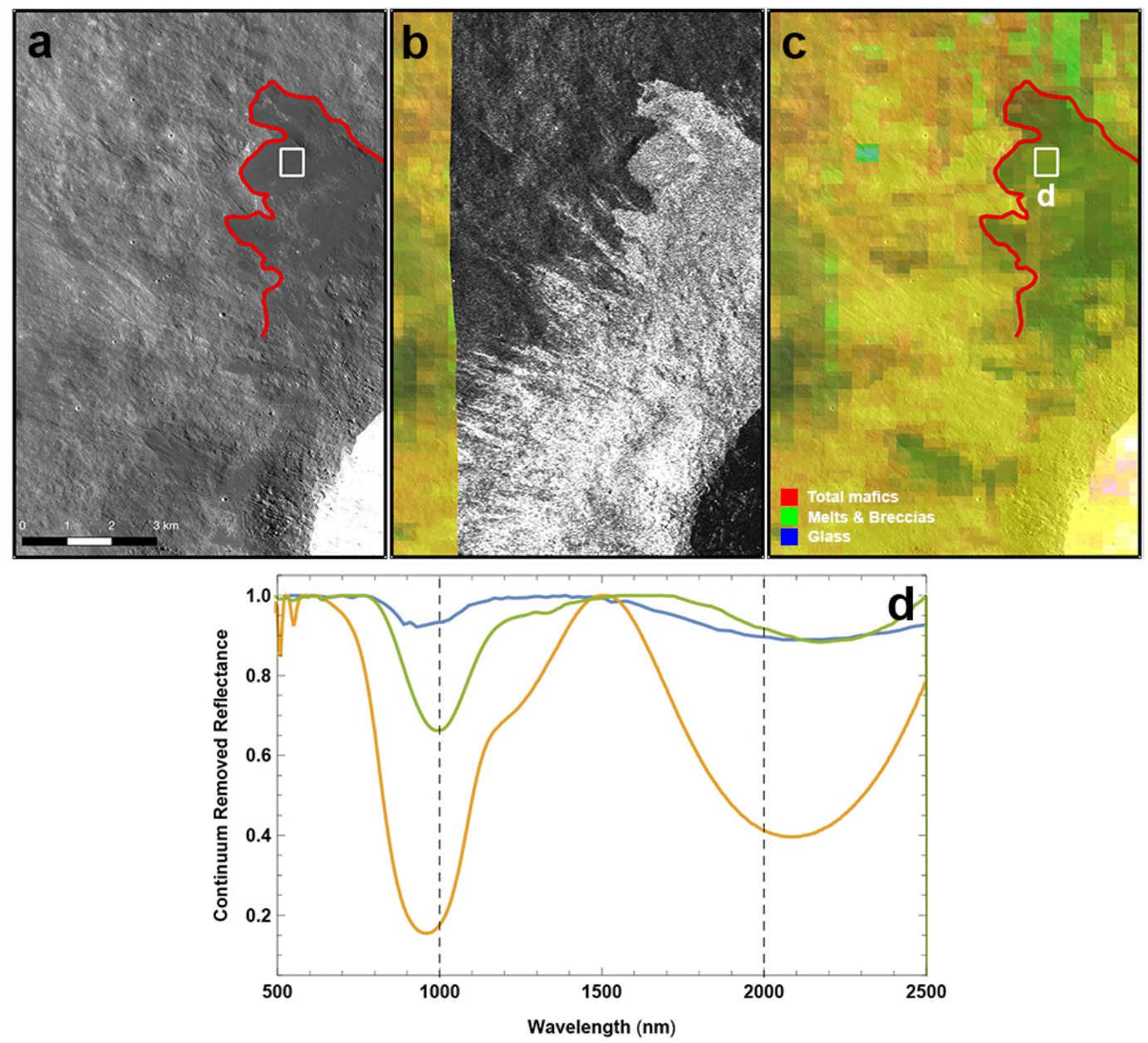

514 Figure 9: (a) LROC NAC image of a prominent melt flow emanating from the 515 northwest rim of Tharp crater (M1107332576.IMG). The lobate portion of the 516 flow has been outlined in red. (b) Mini-RF total power image of the same region 517 indicates the melt deposit is rough at the decimeter scale 518 (LSZ_02832_1CD_XKU_36S146_V1.IMG). (c) Spectral unmixing results of this 519 region suggest the flow is consistent with the melt/breccia endmember (EM4). A 520 white box indicates the region where the spectrum shown in (d) was extracted. (d) 521 Average continuum removed spectrum of a portion of the melt flow from Tharp 522 crater, compared to a clinopyroxene spectrum (sample DL-CMP-011) and the 523 highlands slow quench spectrum given in Figure 4. 

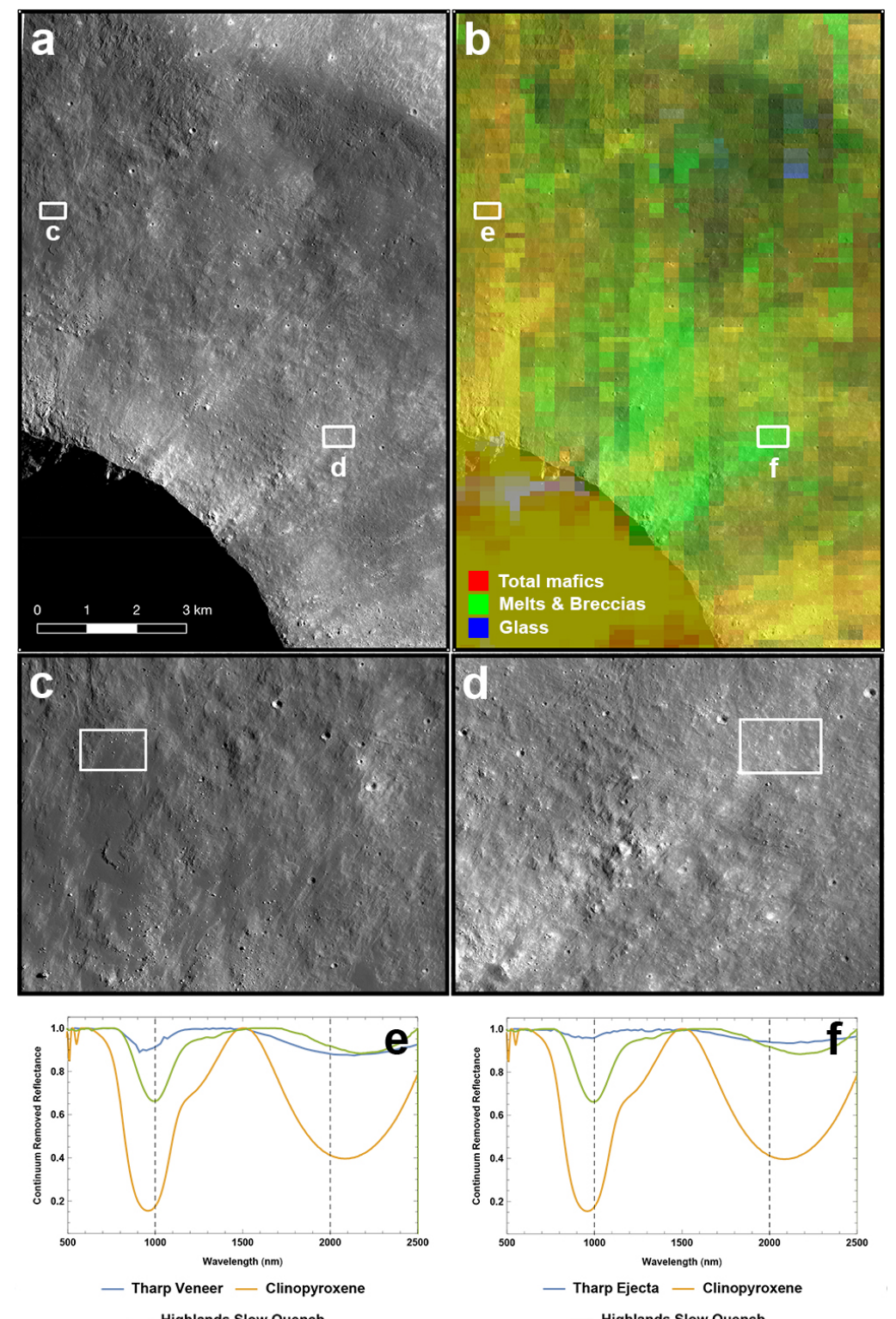

Figure 10: (a) LROC NAC image of ejecta emanating from the northeast rim of Tharp crater (M1183864794.IMG). White boxes indicate the regions shown in the close-ups in (c) and (d), where the spectra in (e) and (f) were extracted. (b) 530 with mafics (EM1 + EM2), while the region labeled (d) appears consistent with 531 melts/breccias (EM4). This is at odds with visual identification of a melt veneer in 532 (c) and boulders in (d). (e, f) Average continuum removed spectra of two portions 533 of the ejecta from Tharp crater, compared to a clinopyroxene spectrum (sample 534 DL-CMP-011) and the highlands slow quench spectrum given in Figure 4. 


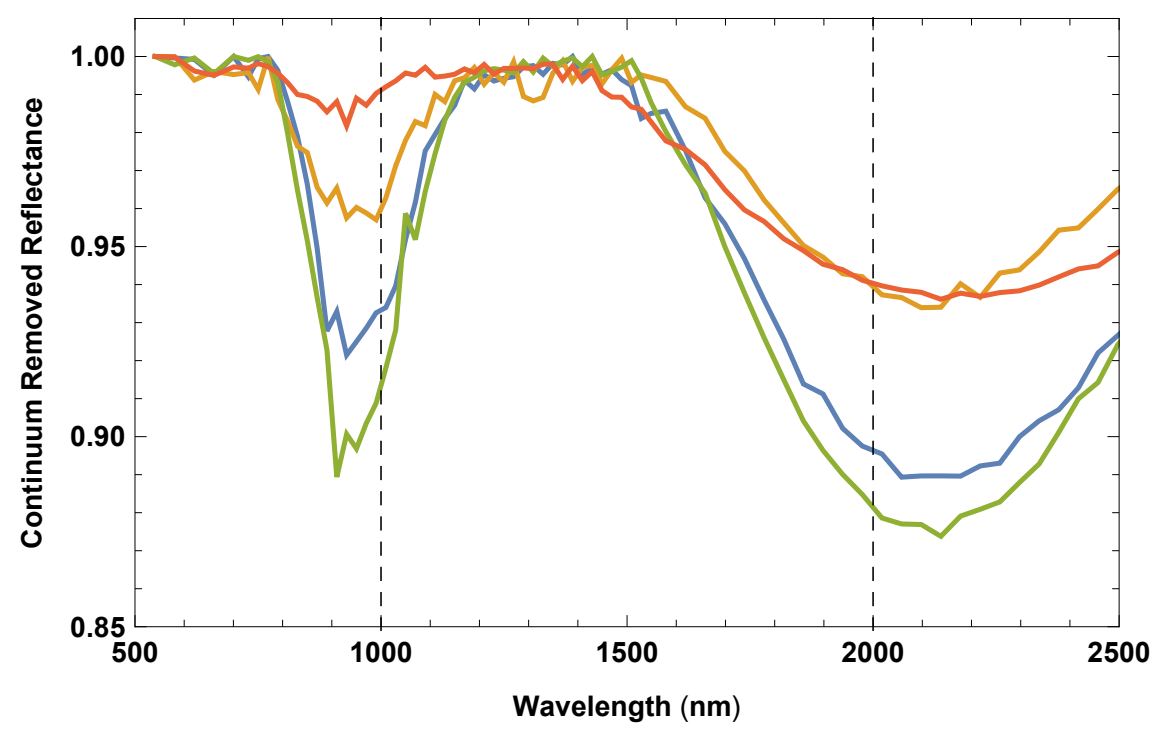

Tharp Melt — Tharp Ejecta

536 Figure 11: Average continuum removed spectra of four regions around Tharp 537 crater. Spectra were extracted from the white boxes given in the top left of Figure $8 \mathrm{~b}$ (soil), Figure 9c (melt), Figure 10e and 10f (ejecta and veneer). 
542

543 Giordano Bruno is a fresh, rayed crater, and possibly the youngest large

544 (D $>20 \mathrm{~km})$ crater on the Moon. Crater counts suggest that it is 1-10 Ma [Morota

545 et al., 2009], or even younger [Plescia et al., 2010]. High resolution observations

546 of Giordano Bruno crater have revealed a wide variety of impact melt

547 morphologies both interior and exterior to the crater rim. In particular, an

548 extensive melt deposit is found south of the crater rim, which ends in an inflated

549 flow margin [Bray et al., 2010]. Recent spectral analysis of the crater found

550 evidence for hydration features associated with the impact melt features at

551 Giordano Bruno, which could be the result of both indigenous and non-indigenous

552 sources of water [Bhiravarasu et al., 2017].

553 When the spectral unmixing model is applied to the $\mathrm{M}^{3}$ data in this region,

554 the ejecta blanket appears to be quite diverse in composition (Figure 12). Portions

555 of the ejecta appear consistent with pyroxene, while other areas (including a large

556 region southeast of the crater) appear consistent with olivine. In terms of the melt

557 deposits, the model identifies a prominent lobate melt flow south of the crater as

558 being most consistent with mafics, predominantly pyroxene with some

559 contributions from olivine (Figure 13). However, the spectral bands in this region

560 are relatively weak and have broad absorption features near 1 and $2 \mu \mathrm{m}$,

561 suggestive of pyroxene mixed with glass and/or other minerals. The band centers 
562 in this region are found at 1.02 and $2.23 \mu \mathrm{m}$, compared to 1.00 and $2.26 \mu \mathrm{m}$ for 563 the clinopyroxene DL-CMP-057 and 1.07 and $1.98 \mu \mathrm{m}$ for the fast-quenched 564 highlands glass.

565 Melt flows and veneers also appear intermixed with the ejecta southeast of

566 the crater, in the region identified as olivine-bearing in the spectral unmixing

567 model (Figure 14). Again, the broad one-micron absorption features in this region

568 are relatively weak. It is therefore likely that the spectral model is interpreting a

569 broad one-micron band as olivine, but it is more likely another component,

570 possibly a mixture containing glass or low-contrast pyroxene. The band centers in

571 the SE1 region are found at 1.05 and $2.11 \mu \mathrm{m}$, while the band centers in the SE2

572 region are found at 1.04 and $2.17 \mu \mathrm{m}$. This can be compared to the band centers at

5731.00 and $2.26 \mu \mathrm{m}$ for the clinopyroxene DL-CMP-057, $1.09 \mu \mathrm{m}$ for the olivine

574 DD-MDD-001, and 1.07 and $1.98 \mu \mathrm{m}$ for the fast-quenched highlands glass. No

575 other surveys have identified olivine in this region [e.g., Isaacson et al., 2011],

576 and it is typically exposed only in and around the rims of large impact basins

577 [Yamamoto et al., 2010]. 


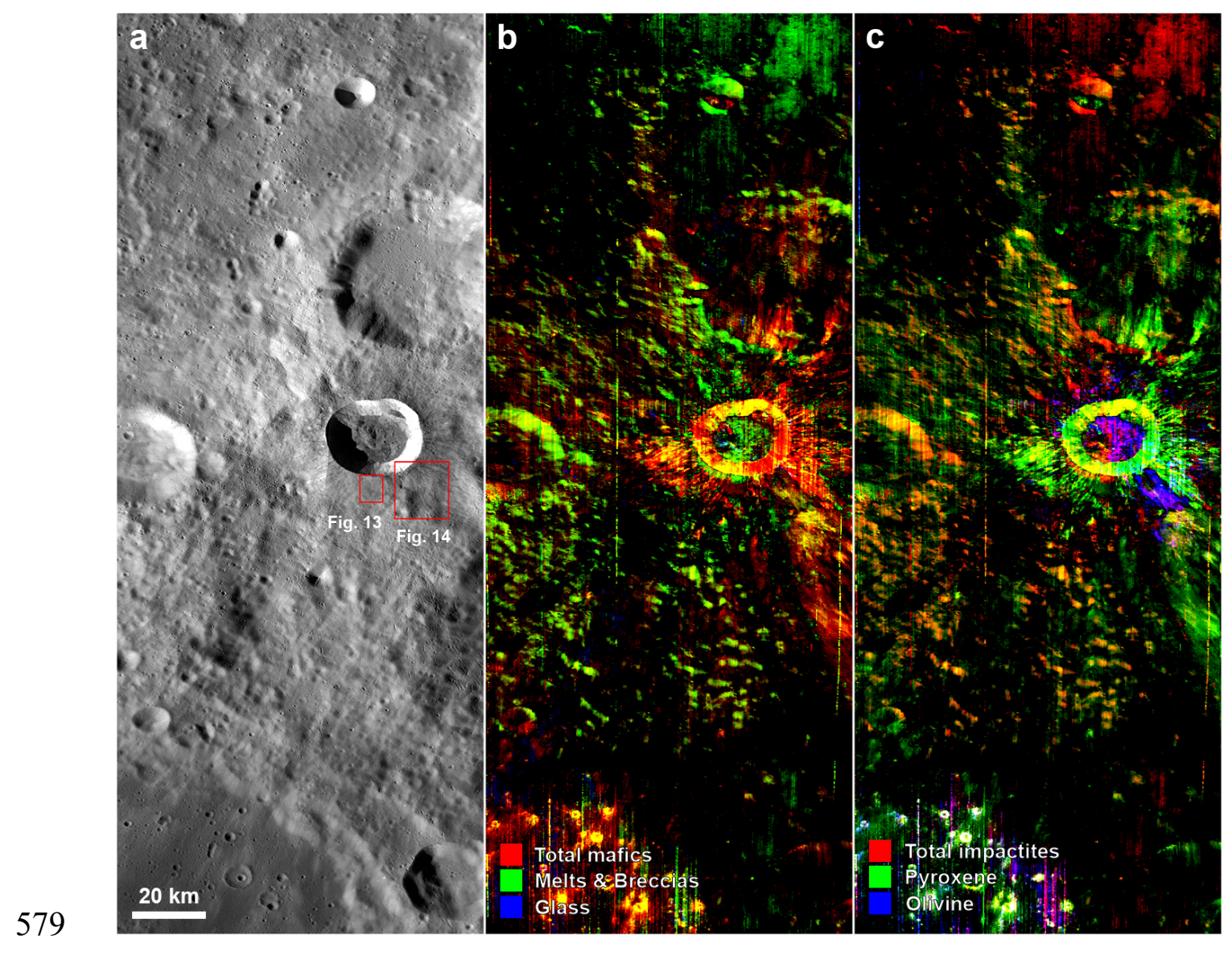

580 Figure 12: (a) LROC WAC mosaic of Giordano Bruno crater. The red boxes 581 indicate the location of Figures 13 and 14. (b) Spectral unmixing results from the $582 \mathrm{M}^{3}$ image M3G20090531T215442_V01_RFL.IMG. Here, red represents the 583 combined mafic endmembers (pyroxenes, EM1, and olivines, EM2), green 584 represents impact melt and breccia endmembers (EM4), and blue represents 585 quenched glass endmembers (EM3). (c) Spectral unmixing results, where red 586 represents the combined impactite endmembers (quenched glass, EM3, and 587 impact melts and breccias, EM4), green represents pyroxene-rich endmembers 588 (EM1), and blue represents olivine-rich endmembers (EM2). The red and blue 589 bands in (b) and the green and blue bands in (c) have been scaled linearly from $590 \quad 0.01$ to their maximum value, to remove spuriously low values. The green band in 591 (b) and the red band in (c) have been scaled linearly from 0.1 to their maximum 592 value. 

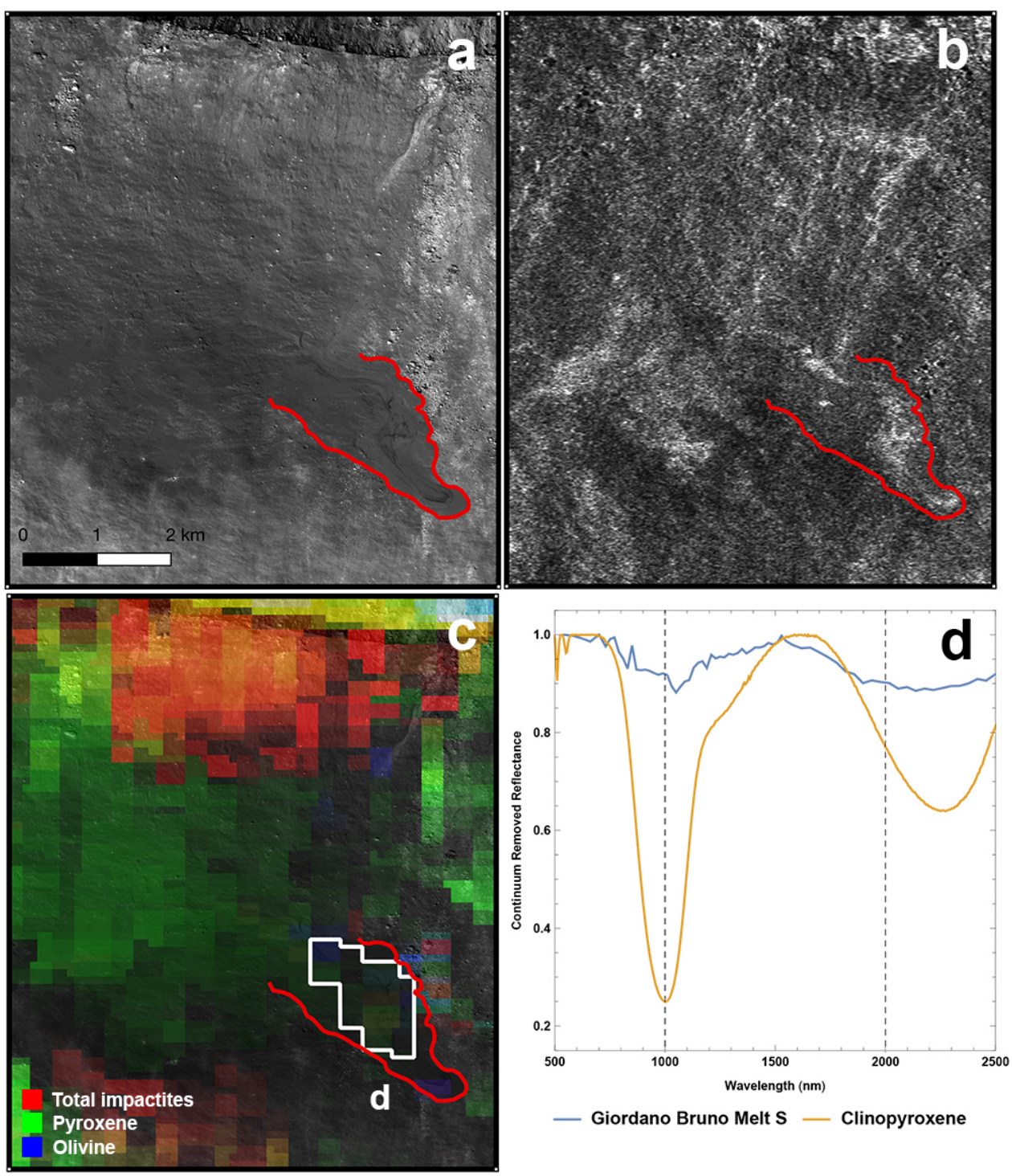

Figure 13: (a) LROC NAC image of a prominent melt flow emanating from the 596 south rim of Giordano Bruno (M106209806RE.IMG). The lobate portion of the flow has been outlined in red. (b) Mini-RF total power image shows decimeter scale roughness variations in the melt deposit, in an otherwise rough ejecta blanket (LSZ_02525_1CD_XKU_37N103_V1.IMG). (c) Spectral unmixing 600 results of this region suggest the flow is consistent with pyroxene (EM1), with 601 some contribution from olivine (EM2). A white box indicates the region where 602 the spectrum shown in (d) has been extracted. (d) Average continuum removed 603 spectrum of a portion of the melt flow from Giordano Bruno (scaled by a factor of 604 four for clarity), compared to a clinopyroxene spectrum given in Figure 4 (sample 605 DL-CMP-057). 


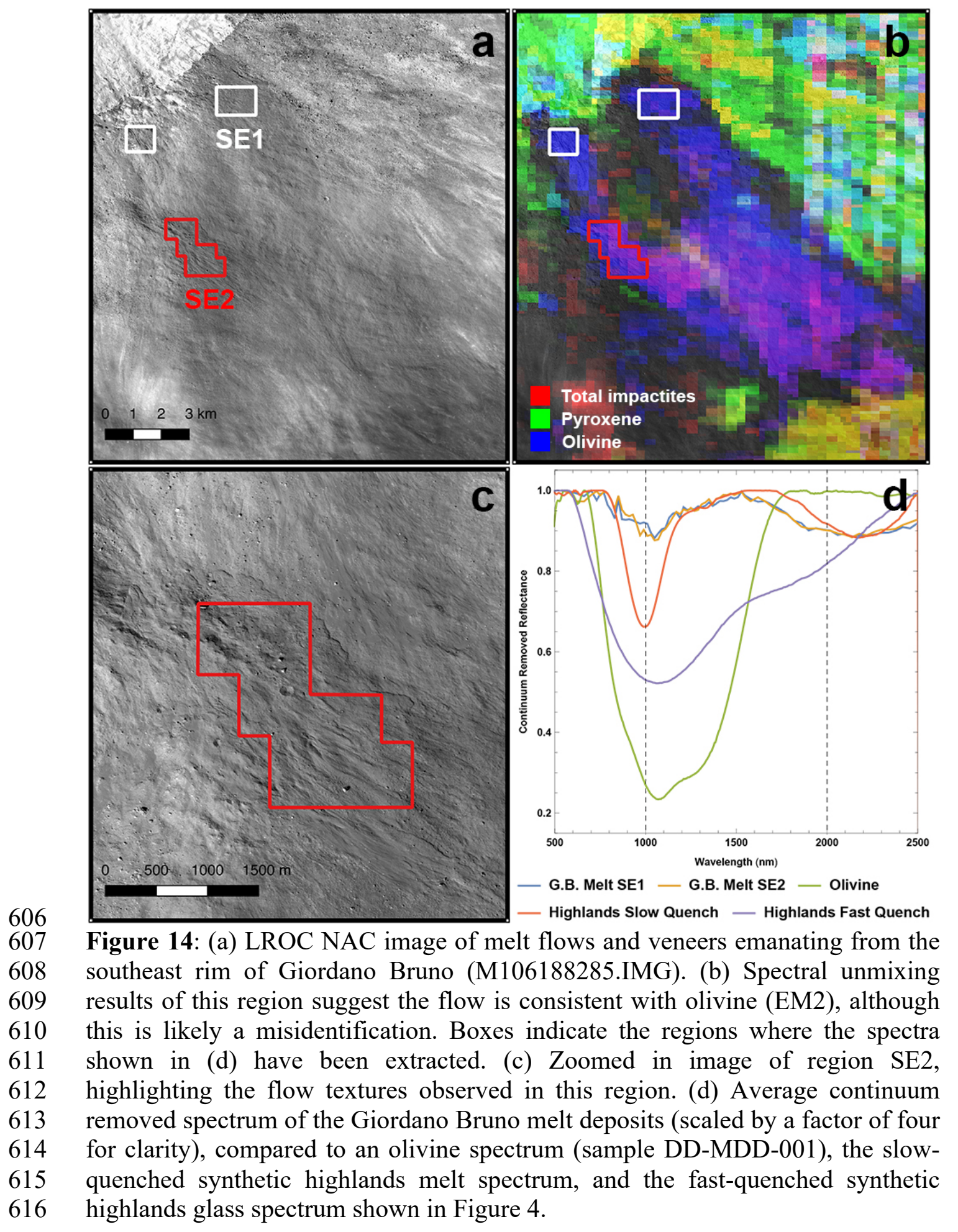


619 Aristarchus Crater is a $42 \mathrm{~km}$ diameter crater that formed on the 620 southeastern margin of the Aristarchus Plateau. The Aristarchus Plateau and the 621 ejecta of Aristarchus crater represent one of the most geologically diverse regions 622 on the Moon, containing evidence for pyroclastic volcanic glasses, mare and 623 plateau materials, and purported high-silica compositions [Zisk et al., 1977; 624 McEwen et al., 1994; Zhang and Jolliff, 2008; Glotch et al., 2010; Horgan et al., 625 2014; Zanetti, 2015]. Geologic and geomorphologic mapping of the crater show a 626 diverse array of impact melt morphologies around the crater (ponds, flows, and 627 veneers) [Zanetti, 2015]. Melt deposits around Aristarchus do not show 628 compositionally unique spectra, but rather appear to adopt compositions similar to 629 the regions of the target from which they were derived [Zanetti, 2015].

630 The reasons for this are unclear, but potential explanations include (1) 631 selective melting of the substrate, (2) recrystallization of the impact melt, and/or 632 (3) the inclusion of lithic clasts during the transport and deposition of the impact 633 melt. The shock metamorphic phenomenon referred to as selective mineral 634 melting is where, for example, all the plagioclase in a rock would be converted 635 into glass and any mafic minerals remain relatively intact; this is plausible as 636 shock pressures need to be much higher to melt pyroxene and olivine when 637 compared to plagioclase [see French, 1998]. However, since the range of shock 
638 pressures needs to be quite limited (e.g., $\sim 45-55 \mathrm{GPa}$ ), selective mineral melting

639 is quite rare amongst impact rocks. This likely rules out the chances of observing 640 a spectral signature of a melt deposit affected by selective mineral melting,

641 especially from orbit. Recrystallization of the melt is also an unlikely explanation.

642 Crystals formed from the cooling and re-crystallization of impact melts are

643 generally restricted to the interior of more voluminous and slowly cooled melt

644 sheets in basin forming impacts $>300 \mathrm{~km}$ in diameter [e.g., Vaughan et al., 2013].

645 In contrast, craters in this study are less than $100 \mathrm{~km}$ in diameter and observations

646 are mainly focused on the less voluminous terrace and exterior melt deposits. On

647 the other hand, the contamination of lithic clasts from the transport and deposition

648 of the impact melt outside of the walls of the transient cavity is likely to be a

649 major contributor to spectral signatures of melt deposits. Analysis of

650 hyperspectral data and high-resolution images of Martian complex craters show

651 that clast-bearing impact melt deposits typically adopt the spectral signature of the

652 materials they flowed over [e.g., Hopkins et al., 2017].

653 Of particular interest at Aristarchus are ejecta deposits of similar 654 composition in the southwestern and eastern parts of the crater that have high 655 albedo and are highly correlated with high-silica Christiansen Feature (CF) 656 signatures in Diviner data [Glotch et al., 2010; Zanetti, 2015]. These areas have 657 been interpreted by previous researchers as impact melt glass [Mustard et al., 658 2011], or spectrally neutral impact melt [Horgan et al., 2014]. However, although 
659 some melt morphologies are present, detailed geomorphologic mapping showed 660 that these areas generally lack widespread flows, ponded melt, or evidence of

661 impact melt veneers. Rather, the correlation with high-silica and low-Fe ejecta

662 suggests that these regions are consistent with more evolved lithologies excavated

663 by the Aristarchus impact event [Zanetti, 2015].

664 When we compare the melt deposit map produced by Zanetti [2015] to our

665 spectral unmixing results (Figure 15), we find no correlation between the location

666 of the melt deposits and any specific spectral signature (Figure 16). In one

667 prominent melt deposit north of the crater $\left(\sim 16.5 \mathrm{~km}^{2}\right.$ in areal extent), the model

668 failed to identify any preferred endmember. As in the Horgan et al. [2014]

669 analysis, our unmixing model suggests the presence of impact melts and breccias

670 southwest of the crater. However, as we describe above, there is little

671 morphological evidence of widespread melt ponds or flows in this region. In

672 Figure 17, we highlight a region with no mapped melt deposits that has a spectral

673 signature consistent with impact melts/breccias. The band centers in this region

674 are found at 0.99 and $2.17 \mu \mathrm{m}$, compared to 0.99 and $2.19 \mu \mathrm{m}$ for the slow-

675 quenched synthetic highlands melt. If melt is present, it must be a very thin layer,

676 or intimately mixed with the ejecta. However, it is also possible that the unusual

677 chemistry at the site of Aristarchus is producing spectrally bland signatures not

678 representative of compositions found elsewhere on the Moon, confusing spectral

679 models. Glass spectra tend to be low contrast and verging on spectrally bland 
680 themselves, so any spectrally bland unit on the lunar surface can be matched to 681 these spectra. This result emphasizes the need to correlate spectral results to 682 mapping conducted using other data sets, which are capable of identifying 683 morphological evidence of impact melt deposits (such as high-resolution visible 684 imagery or radar data).

685 As in previous studies [e.g., McEwen et al., 1994; Mustard et al., 2011;

686 Horgan et al., 2014], we also identify olivine in a region southeast of the crater.

687 This region is associated with a comparatively low albedo portion of the ejecta 688 blanket (Figure 18). However, this region was investigated in high-resolution 689 NAC images and no melt veneers were identified based on their morphology 690 (although our spectral mixing model supports the presence of both olivine and 691 impactites in this region). As in the region southwest of the crater, if melt is 692 present, it must be thinner than the typical veneer or intimately mixed with the 693 ballistic component of the ejecta. Finally, the model identifies the presence of 694 quenched glass north of Aristarchus (Figure 15). This glass is associated with the 695 pyroclastic activity concentrated in this region [e.g., Zisk et al., 1977; Gaddis et 696 al., 1985; Campbell et al., 2008]. This identification gives us confidence that the 697 model can recognize quenched glass where present.

698 Note that we do not present radar data for Aristarchus here, because the 699 entire ejecta blanket is radar bright and it is therefore difficult to discern the radar 700 bright impact melt deposits from the radar bright blocky ejecta. See Carter et al. 
701 [2017] for Arecibo and Mini-RF images of Aristarchus.

702
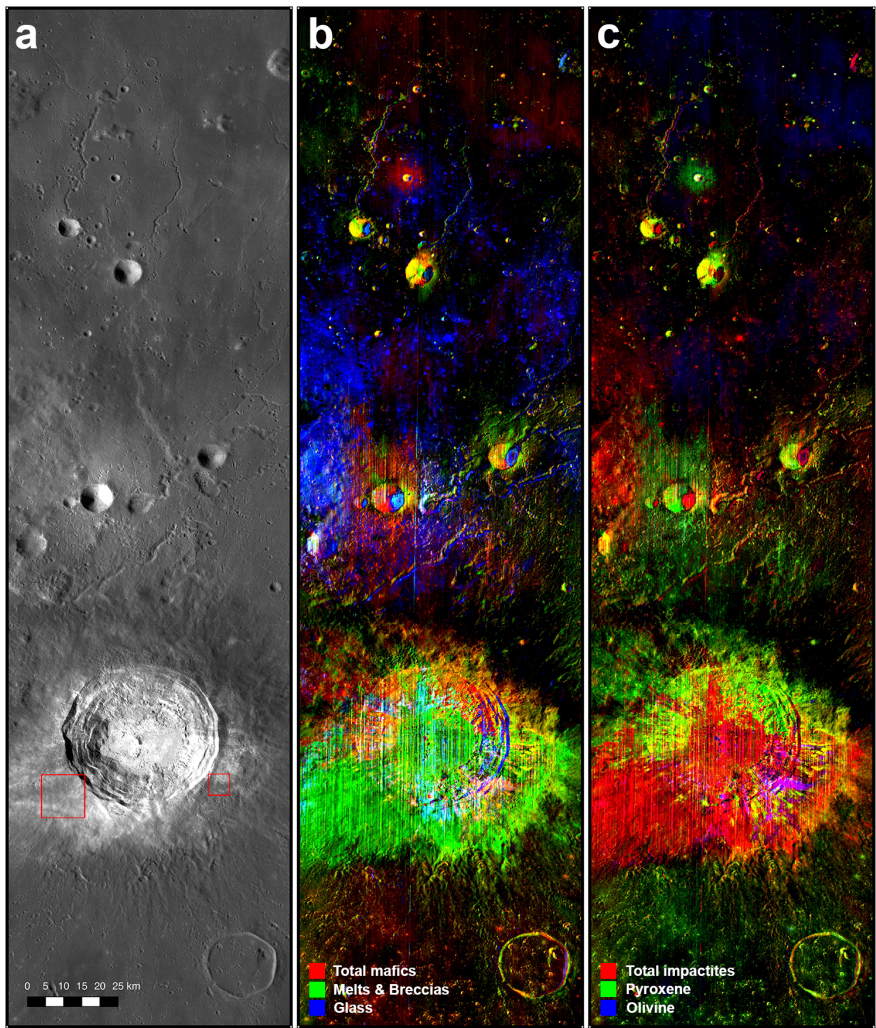

Figure 15: (a) LROC WAC mosaic of Aristarchus crater. The red boxes indicate the location of Figures 17 (left) and 18 (right). (b) Spectral unmixing results from M3G20090209T072710_V01_RFL.IMG. Here, red represents the combined mafic endmembers (pyroxenes, EM1, and olivines, EM2), green represents impact melt and breccia endmembers (EM4), and blue represents quenched glass endmembers (EM3). (c) Spectral unmixing results, where red represents the combined impactite endmembers (quenched glass, EM3, and impact melts and breccias, EM4), green represents pyroxene-rich endmembers (EM1), and blue represents olivine-rich endmembers (EM2). All bands have been scaled linearly from 0.01 to their maximum value, to remove spuriously low values. 

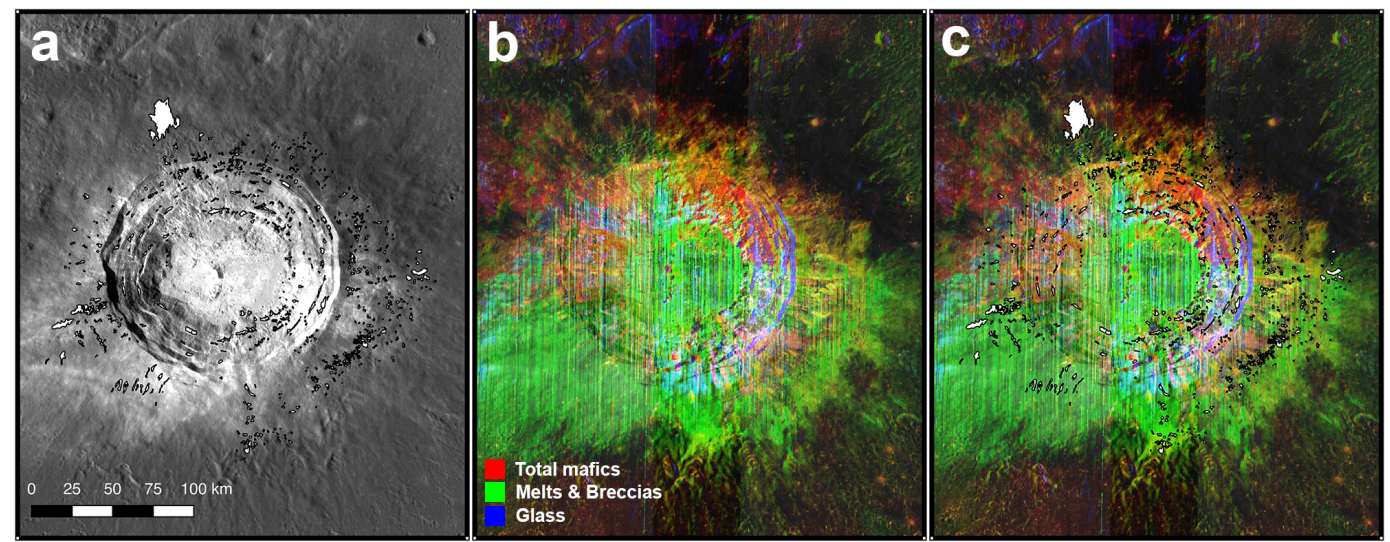

Figure 16: (a) LROC WAC mosaic of Aristarchus crater, showing the locations of melt deposits identified by Zanetti [2015]. The melt is shown in white with

719 black outlines. (b) Spectral unmixing model results of the same region, without 720 and (c) with the melt deposits labeled.
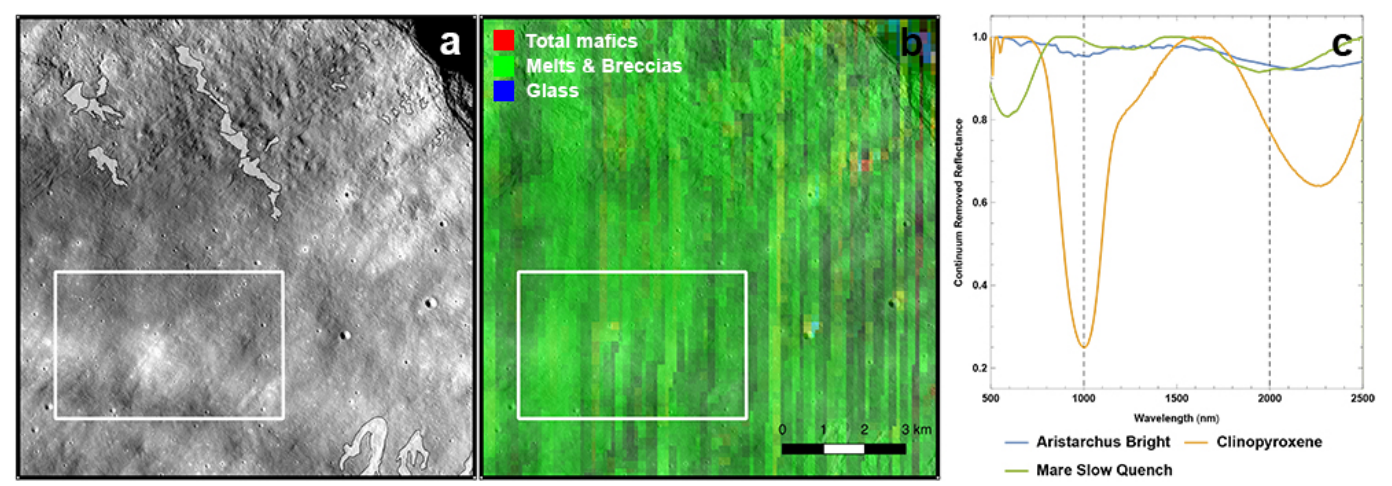

Figure 17: (a) LROC NAC image of the bright ejecta southwest of Aristarchus

725 indicates the region where the spectrum shown in (c) has been extracted. (b)

726 Spectral unmixing results of this region suggest the flow is consistent with impact

727 melts and breccias (EM4). (c) Average continuum removed spectrum of the

728 Aristarchus bright ejecta, compared to a clinopyroxene spectrum (sample DL-

729 CMP-057) and the mare slow quench spectrum given in Figure 4. 


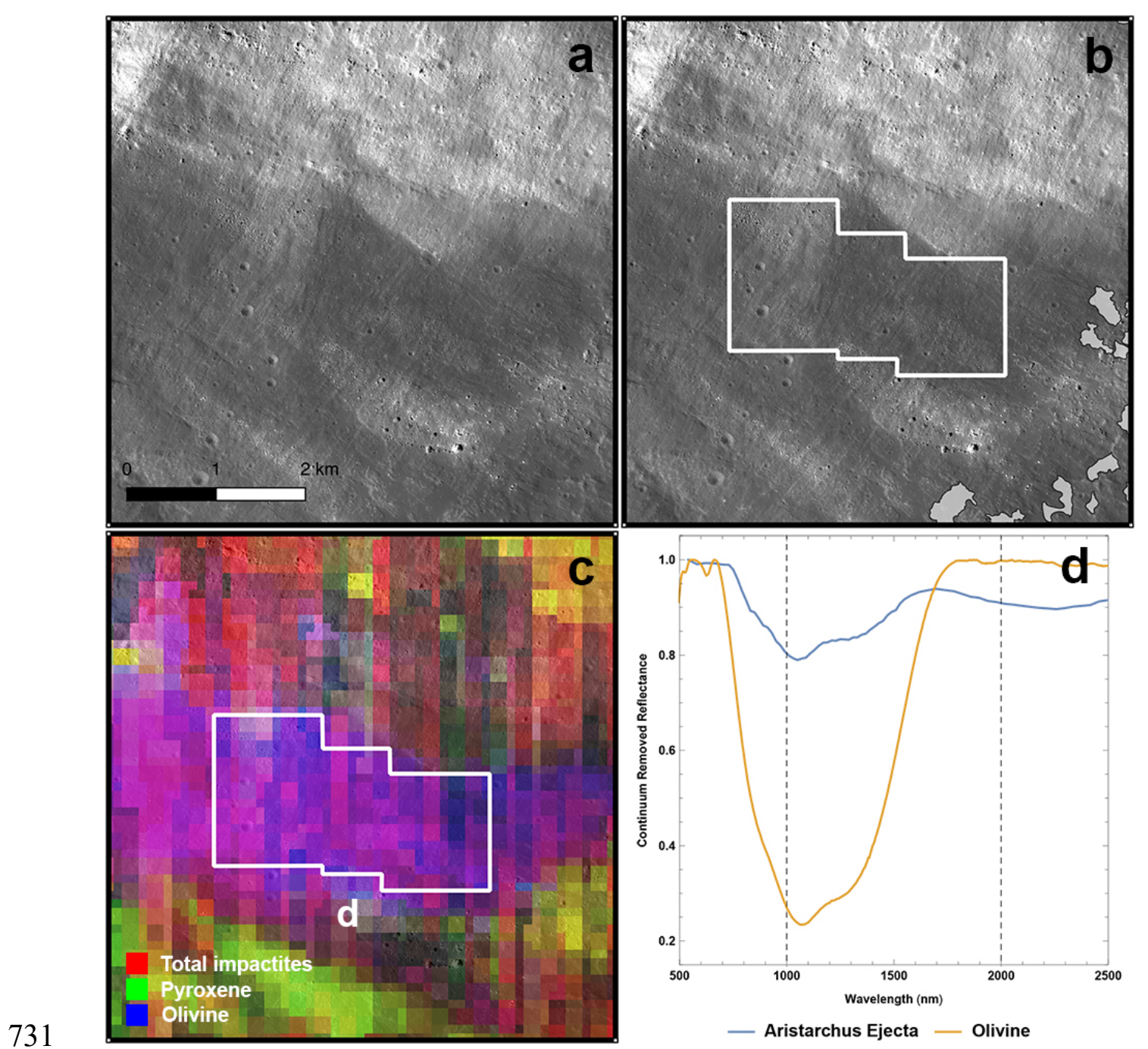

732 Figure 18: (a) LROC NAC image of an olivine-rich portion of the ejecta on the 733 southeast rim of Aristarchus (M1191003838.IMG). (b) The same image from (a), 734 with prominent melt deposits identified in gray. A box indicates the region where 735 the spectrum shown in (d) has been extracted. (c) Spectral unmixing results of this 736 region are consistent with the olivine endmember (EM2). (d) Average continuum 737 removed spectrum of the Aristarchus ejecta, compared to an olivine spectrum 738 from Figure 4 (sample DD-MDD-001). 
Glushko (formerly known as Olbers A) is a relatively young $43 \mathrm{~km}$

745 diameter crater located near the highlands/mare boundary, likely Copernican in 746 age [Neish et al., 2013]. Extensive impact melts are observed to the north of the 747 crater rim [Hawke and Head, 1977], easily observed as radar bright deposits in S-

748 Band images of the Moon [Campbell et al., 2010; Neish et al., 2013]. The radar

749 data show a prominent lobate deposit flowing around local topography about 40

$750 \mathrm{~km}$ north and west of the edge of the continuous ejecta blanket [Campbell et al., 751 2010]. The Glushko melt flow has a circular polarization ratio near one at $70 \mathrm{~cm}$ 752 and in excess of one at $12.6 \mathrm{~cm}$, indicating a blocky surface texture at the 753 decimeter to meter scale [Campbell et al., 2010].

754 This lobate deposit is also easily observed in our spectral unmixing model 755 results from the $\mathrm{M}^{3}$ data in this region (Figure 19). This region is identified as 756 being spectrally consistent with impact melts and breccias, and is clearly distinct 757 in composition from the surrounding highlands terrain (Figure 20). We extracted 758 an average spectrum from a portion of this melt unit and find that it has spectral

759 characteristics that are most consistent with the melts plus breccias endmember 760 (EM4) (Figure 21). The band centers in this region are found at 1.00 and $2.24 \mu \mathrm{m}$, 761 compared to 1.00 and $2.26 \mu \mathrm{m}$ for the clinopyroxene DL-CMP-057 and 0.99 and $762 \quad 2.19 \mu \mathrm{m}$ for the slow-quenched synthetic highlands melt. 


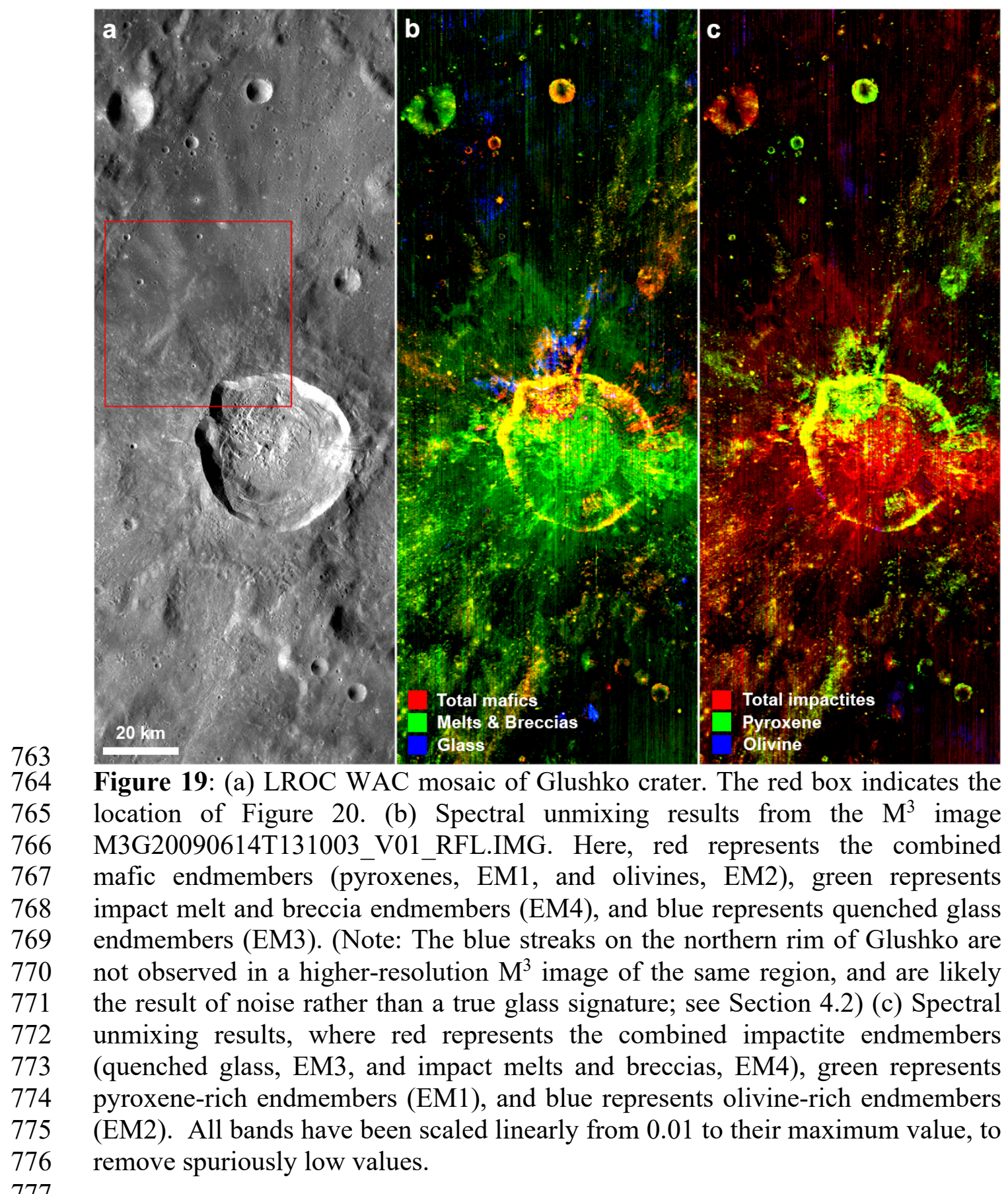



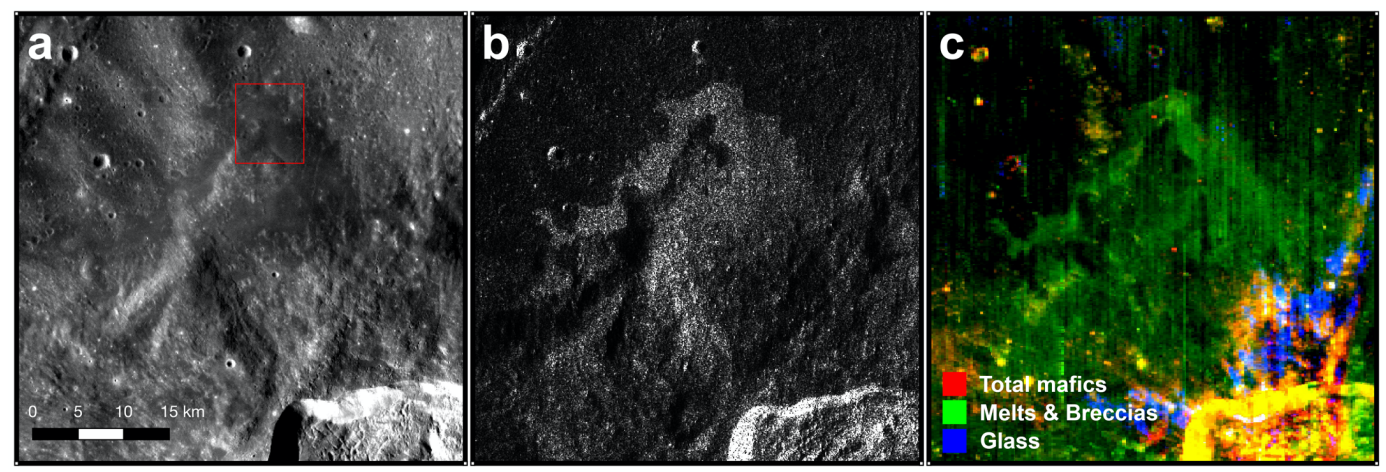

Figure 20: (a) LROC WAC mosaic of the melt flow north of Glushko crater. A 780 red box indicates the location of Figure 21. (b) The melt flow is radar bright in an 781 S-Band same sense radar backscatter image acquired from Arecibo 782 (sband_12n270_scp.img), suggesting a blocky surface at the decimeter scale. (c) 783 Spectral unmixing model results suggest the melt flow has a spectral signature 784 consistent with the impact melts/breccia endmember (EM4).

785
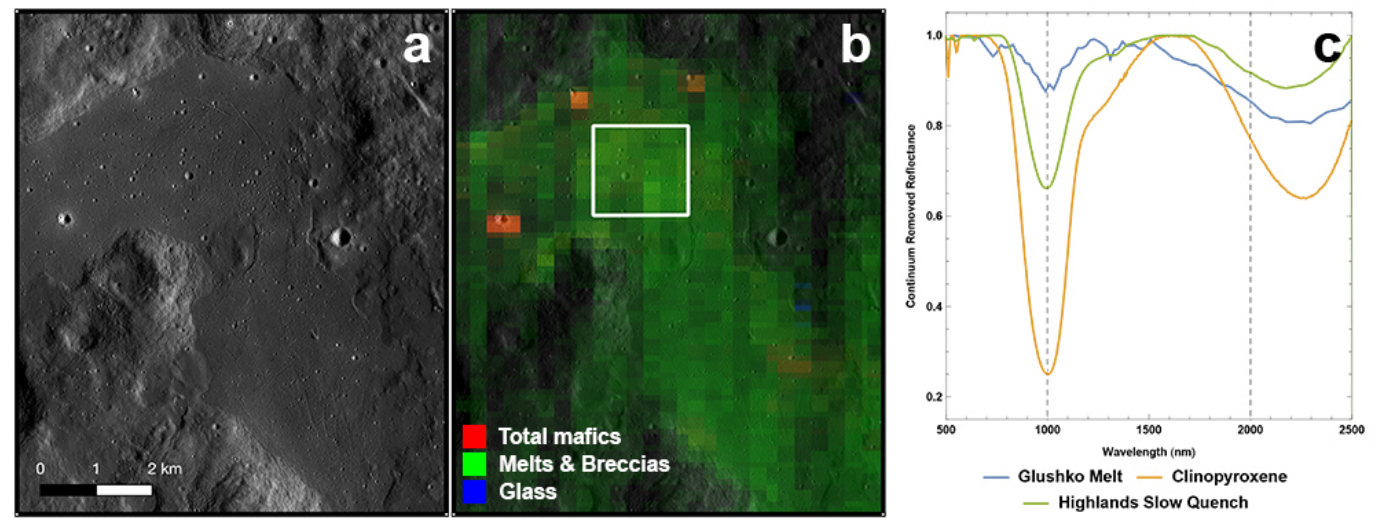

Figure 21: (a) LROC NAC image of a prominent melt flow emanating from the north rim of Glushko (M1108789729.IMG). (b) Spectral unmixing results of this

789 region suggest the flow is consistent with the impact melts and melt breccias 790 endmember (EM4). A white box indicates the region where the spectrum shown in (c) has been extracted. (c) Average continuum removed spectrum of a portion of the melt flow from Glushko (scaled by a factor of four for clarity), compared to a clinopyroxene spectrum (sample DL-CMP-057) and the highlands slow quench spectrum given in Figure 4.

795 
King is a $76 \mathrm{~km}$ diameter complex crater located in the lunar highlands, of

800 Late Eratosthenian to Copernican age [Ashley et al., 2012]. King possesses a large

801 external deposit of impact melt to the north-northwest of the crater, ponded over

802 an area of $\sim 300 \mathrm{~km}^{2}$ [Ashley et al., 2012]. Like most complex craters on the

803 Moon, the impact melt deposit is located just beyond the lowest portion of the

804 rim, likely pushed up and over the rim during the modification stage of impact

805 crater formation [Neish et al., 2014]. Known as the Al-Tusi melt pond, it is

806 characterized by flow features and viscoid forms, as well as hills and domes,

807 craters with anomalous morphologies, and negative relief features possibly

808 associated with near-surface caverns [Hawke and Head, 1977; Heather and

809 Dunkin, 2003; Ashley et al. 2012]. The melt pond has high radar backscatter and

810 circular polarization ratios, indicating that it is rough at the decimeter scale

811 (Figure 22).

812 When the spectral unmixing model is applied to a $\mathrm{M}^{3}$ image of King 813 crater, the Al-Tusi melt pond does not appear to be consistent with any of the

814 endmembers used in our model (Figure 23). However, spectra from this region

815 suggest the presence of pyroxene, either in a pure form or mixed with low816 contrast glass or plagioclase (Figure 24). The band centers in this region are found

817 at 1.02 and $2.26 \mu \mathrm{m}$, compared to 1.00 and $2.26 \mu \mathrm{m}$ for the clinopyroxene DL- 
818 CMP-057. In addition, there is a sinuous feature connecting the crater to the melt

819 pond. This feature has a spectral signature most consistent with pyroxene, with

820 some contribution from melts plus breccias (Figure 24). The band centers here are

821 comparable to those in the pond, at 1.01 and $2.24 \mu \mathrm{m}$. This feature may represent

822 an outcrop of bedrock on the crater rim, exposing pyroxene, or possibly a melt

823 flow contaminated with pyroxene-rich clasts. The addition of pyroxene-rich clasts

824 would give the feature a different spectral signature than the surrounding melt

825 deposits. The feature is not well-defined in the LROC NAC image, although

826 evidence for melt is present in this region, including lower albedo and cooling

827 cracks. The deposit appears to terminate in a lobate margin within the melt pond.

828

829
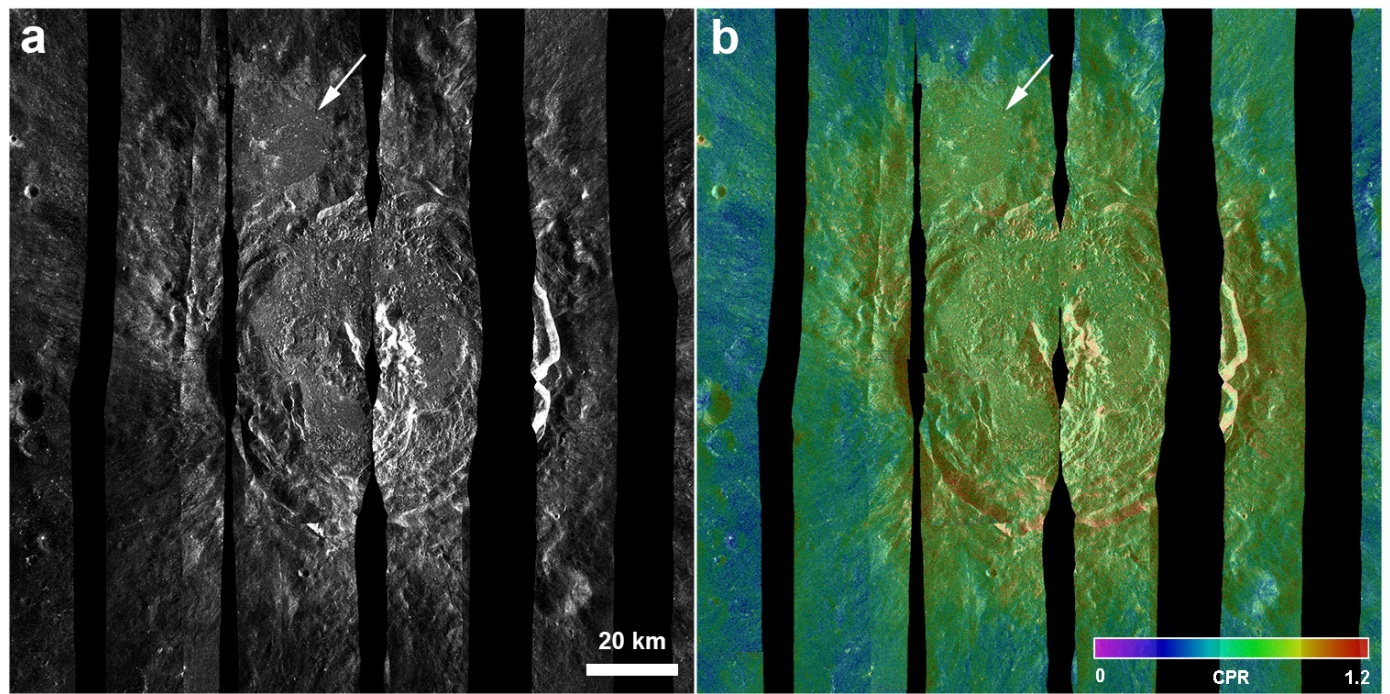

830 Figure 22: (a) Mini-RF same sense radar backscatter image of King crater. An

831 arrow indicates the location of the Al-Tusi melt pond. (b) The high circular 832 polarization ratio $(\mathrm{CPR})$ of the melt pond indicates that it is rough at the decimeter 833 scale. 

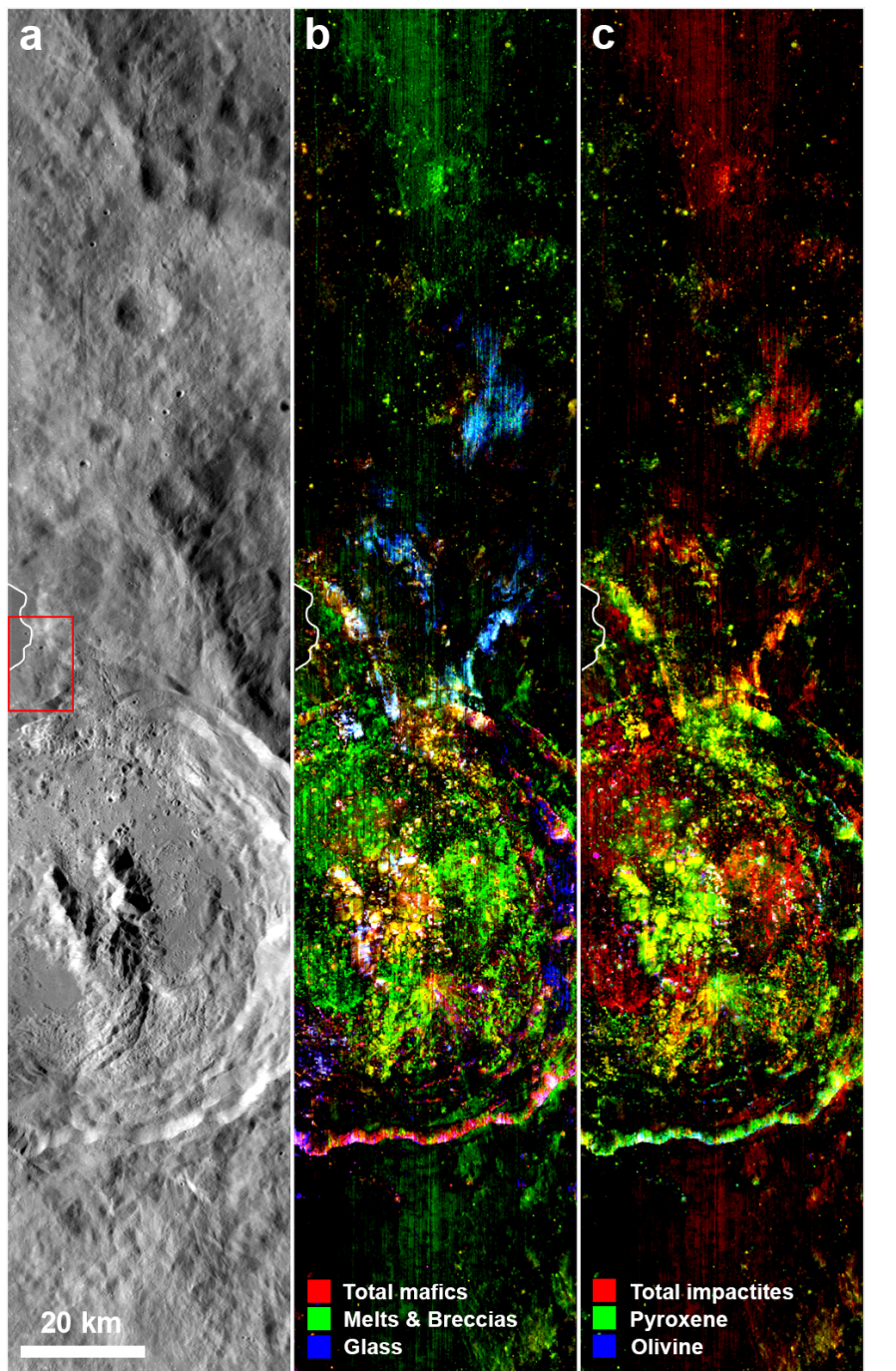

Figure 23: (a) LROC WAC mosaic of King crater. The red box indicates the location of Figure 24. The Al-Tusi melt pond is only partially covered in the scene and outlined in white. (b) Spectral unmixing results from the $\mathrm{M}^{3}$ image M3G20081231T034148_V01_RFL.IMG. Here, red represents the combined mafic endmembers (pyroxenes, EM1, and olivines, EM2), green represents impact melt and breccia endmembers (EM4), and blue represents quenched glass endmembers (EM3). (c) Spectral unmixing results, where red represents the combined impactite endmembers (quenched glass, EM3, and impact melts and breccias, EM4), green represents pyroxene-rich endmembers (EM1), and blue represents olivine-rich endmembers (EM2). The red and blue bands in (b) and the green and blue bands in (c) have been scaled linearly from 0.01 to their maximum value, to remove spuriously low values. The green band in (b) and the red band in (c) have been scaled linearly from 0.05 to their maximum value. 


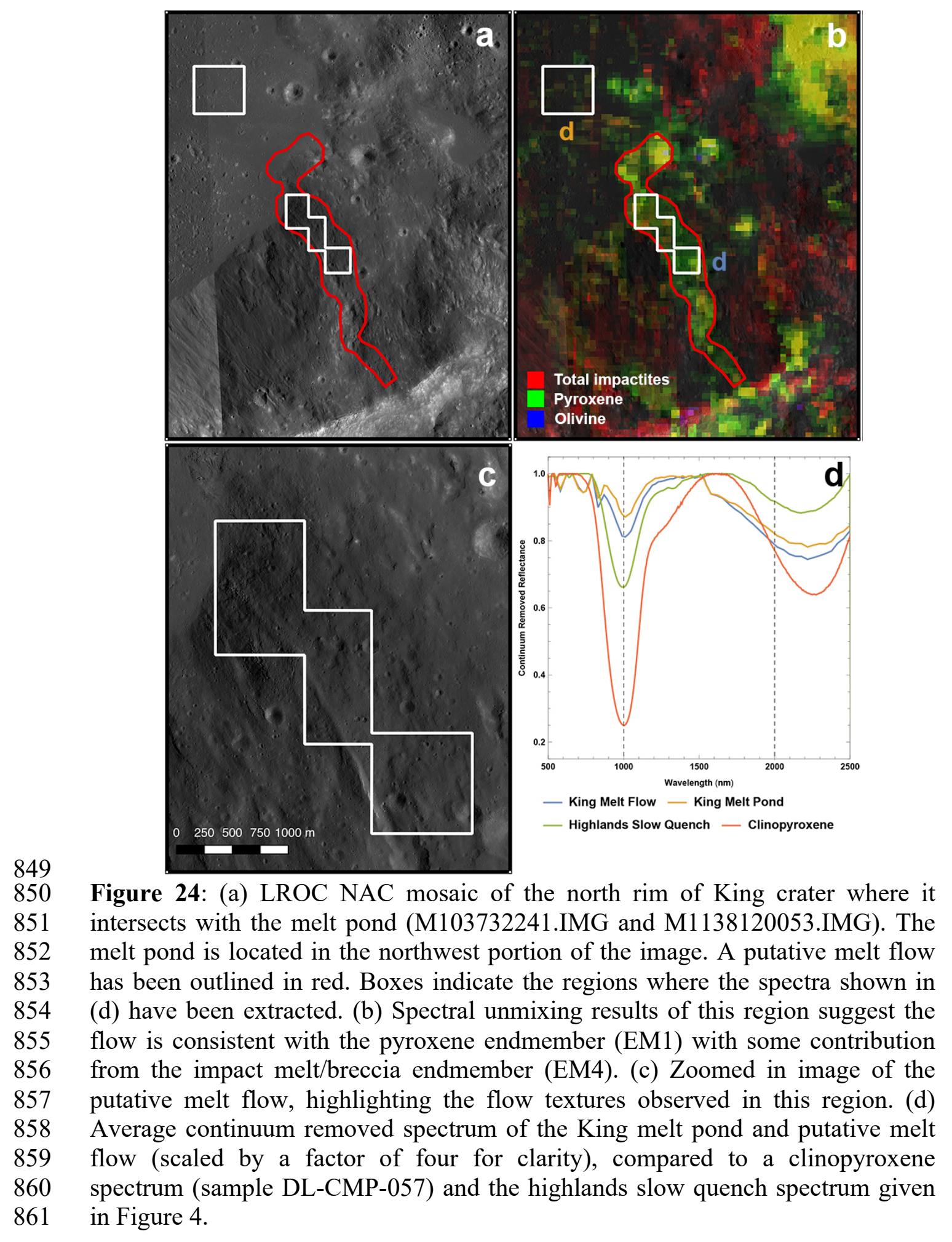


864 Copernicus is a $93 \mathrm{~km}$ diameter rayed crater in eastern Oceanus

865 Procellarum. Evidence for glass in the crater-fill deposits at Copernicus was first 866 argued for by Smreker and Pieters [1985]. Using ground-based near-infrared 867 spectra, they identified "anomalous" reflectance spectra on the floor of 868 Copernicus, characterized by a broad absorption line near one micron. They 869 interpreted these anomalous spectra as indicating the presence of pyroxene, Fe870 bearing glass, and Fe-bearing feldspar. More recent work by Dhingra et al. [2013]

871 using $\mathrm{M}^{3}$ data also speculates on the presence of glass in the interior of

872 Copernicus crater, again noting the presence of a broad one-micron band in 873 certain regions.

874 When our spectral unmixing model is applied to the $\mathrm{M}^{3}$ data in this crater, 875 several spectrally distinct regions are noted (Figure 25). First, the large 876 mineralogically distinct impact melt flow first described by Dhingra et al. [2013] 877 appears as a region consistent with pyroxene. This is in line with the 878 interpretations of Dhingra et al. [2013], who identified the flow as a Mg-rich

879 pyroxene. This region stands out in our spectral unmixing model because its 880 mineral composition differs from that of the surrounding rocks.

881 Second, two small impact craters just west of the flow have ejecta blankets 882 that are consistent with the quenched glass endmember (EM3). These craters were 
883 also associated with broad one micron bands in Dhingra et al. [2013]. It is

884 possible that the craters generated glass-rich impact melt, which remains visible in

885 their ejecta blankets, or they are excavating glass rich materials from the

886 Copernicus melt sheet. Alternatively, the spectral interpretation of glass from the

887 unmixing model is incorrect. Dhingra et al. [2013] suggested this spectral feature

888 may also be consistent with clinopyroxene. Although the spectral features are not

889 as deep as those of a pure clinopyroxene spectrum, they do have similar band

890 centers (Figure 26). The band centers for this region are located at 1.00 and 2.16

$891 \mu \mathrm{m}$, compared to 1.00 and $2.26 \mu \mathrm{m}$ for the clinopyroxene DL-CMP-057 and 0.96

892 and $2.09 \mu \mathrm{m}$ for the clinopyroxene DL-CMP-011.

893 Finally, a large melt flow emanating from the south rim of Copernicus is

894 spectrally consistent with the pyroxene endmember (Figure 27). As with the melt

895 flow at Donner M, this may not be a completely crystalline exposure of pyroxene,

896 but rather a mix of glass and pyroxene. The band centers for this region are

897 located at 0.96 and $2.18 \mu \mathrm{m}$, compared to 0.96 and $2.09 \mu \mathrm{m}$ for the clinopyroxene

898 DL-CMP-011. The Mini-RF data in this region shows a high circular polarization

899 ratio, suggesting that the melt flow is rough at the decimeter scale (Figure 27).

900 Note that this melt flow is one of the only flows yet recognized with blocks

901 visible around its edges, likely increasing the CPR there. In addition, the steep

902 slopes associated with this flow will increase the local incidence angle of the

903 radar, which would increase its circular polarization ratio [see Carter et al., 2009]. 

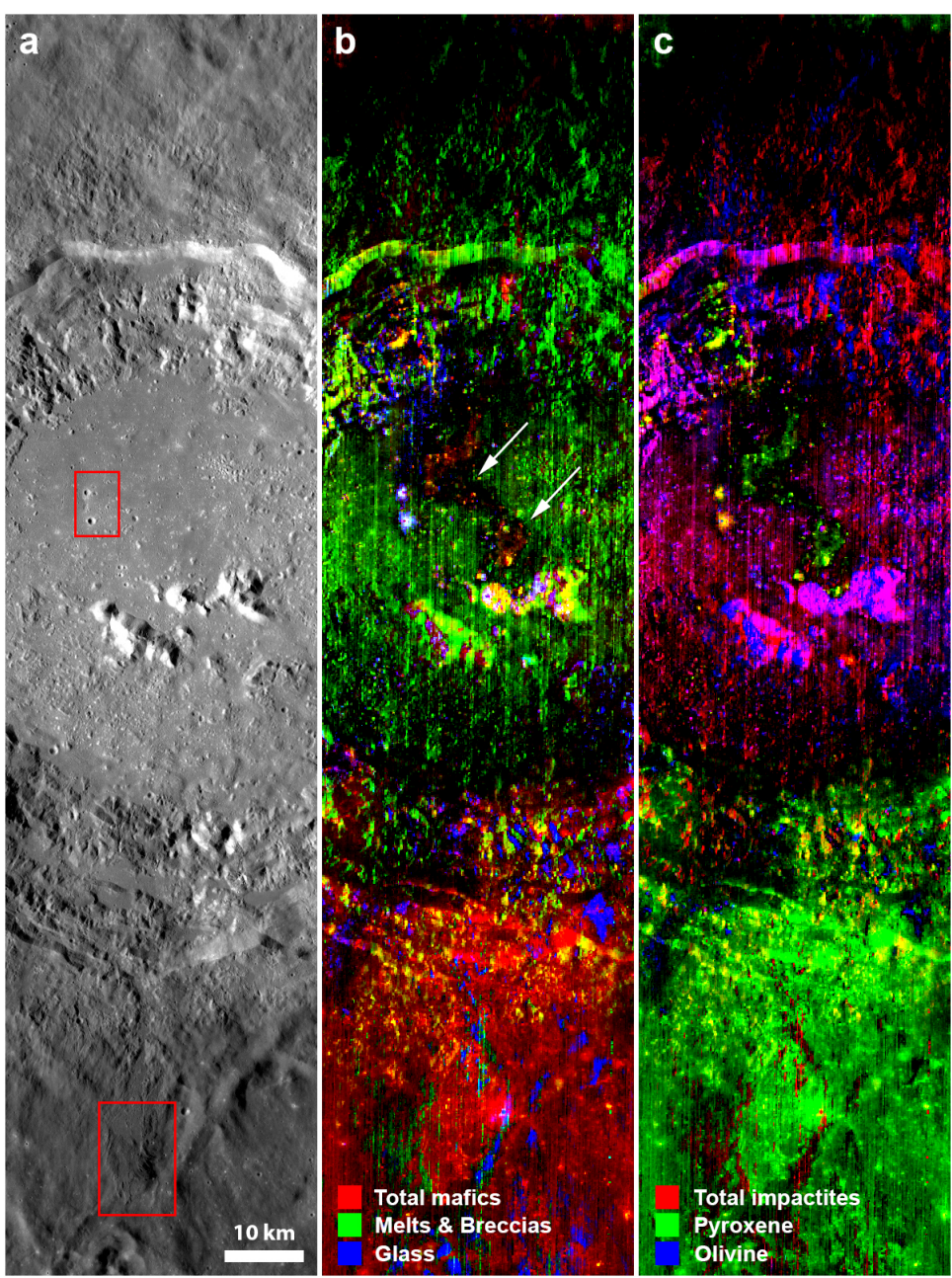

906 Figure 25: (a) LROC WAC mosaic of Copernicus crater. The red boxes indicate 907 the location of Figures 26 (top) and 27 (bottom). (b) Spectral unmixing results 908 from the $\mathrm{M}^{3}$ image M3G20090207T044515_V01_RFL.IMG. Here, red represents 909 the combined mafic endmembers (pyroxenes, EM1, and olivines, EM2), green 910 represents impact melt and breccia endmembers (EM4), and blue represents 911 quenched glass endmembers (EM3). White arrows indicate the mineralogically 912 distinct melt flow first identified by Dhingra et al. [2013]. (c) Spectral unmixing 913 results, where red represents the combined impactite endmembers (quenched 914 glass, EM3, and impact melts and breccias, EM4), green represents pyroxene-rich 915 endmembers (EM1), and blue represents olivine-rich endmembers (EM2). The 916 red and blue bands in (b) and the green and blue bands in (c) have been scaled 917 linearly from 0.01 to their maximum value, to remove spuriously low values. The 918 green band in (b) and the red band in (c) have been scaled linearly from 0.1 to 919 their maximum value. 

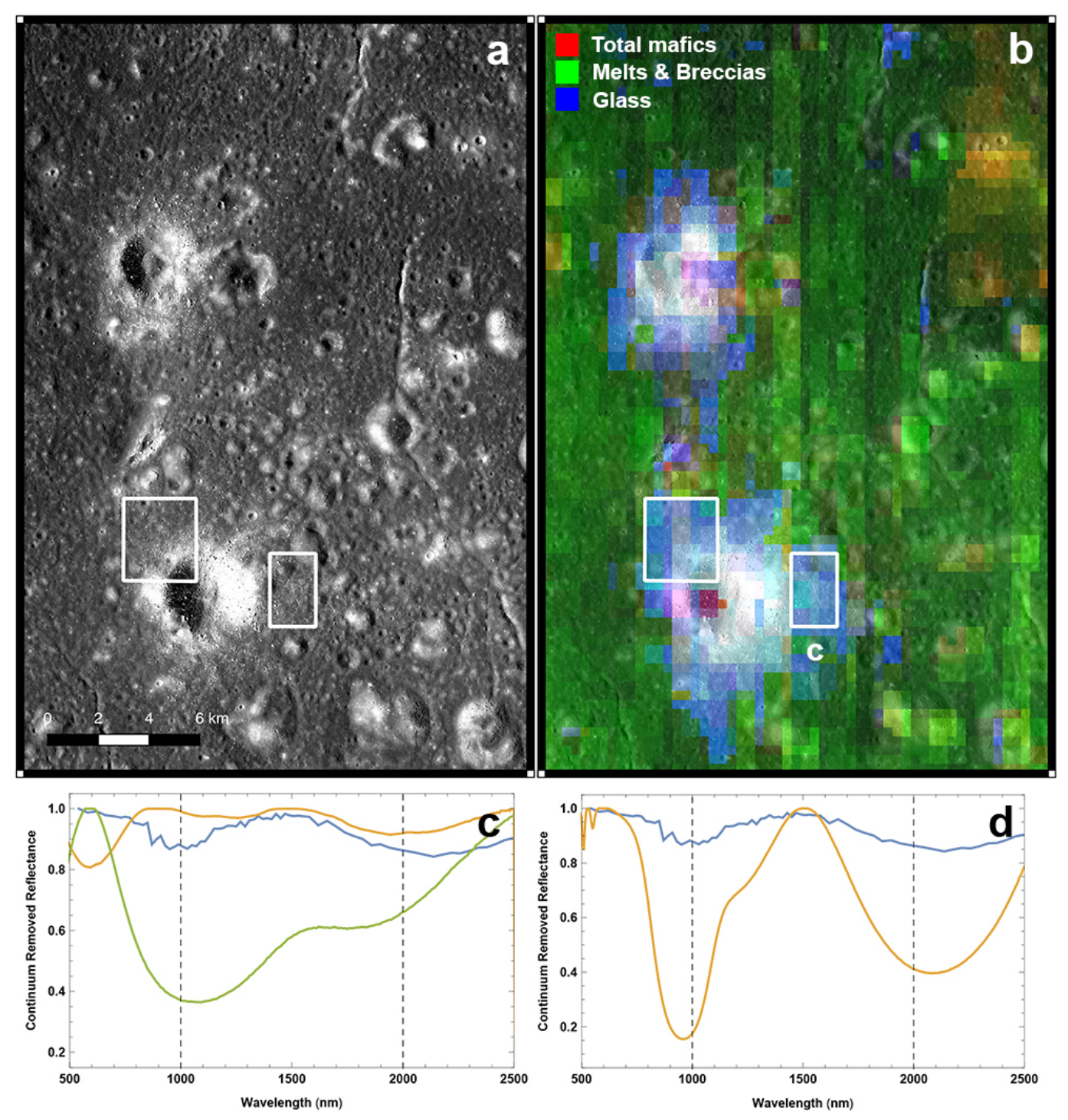

- Copernicus Crater — Mare Slow Quench — Mare Fast Quench

- Copernicus Crater — Clinopyroxene

Figure 26: (a) LROC NAC image of a small crater located on the floor of 922 Copernicus crater (M1175545925LE.IMG). (b) Spectral unmixing results of this 923 region suggest the crater's ejecta is consistent with the quenched glass 924 endmember (EM3). Two white boxes indicate the combined region where the 925 spectrum shown in (c) and (d) was extracted. (c) Average continuum removed 926 spectrum of a portion of the small Copernicus crater (scaled by a factor of two for 927 clarity), compared to the slow-cooled mare melt and quenched mare glass given 928 in Figure 4, and (d) a clinopyroxene spectrum from Figure 4 (sample DL-CMP929 011). 

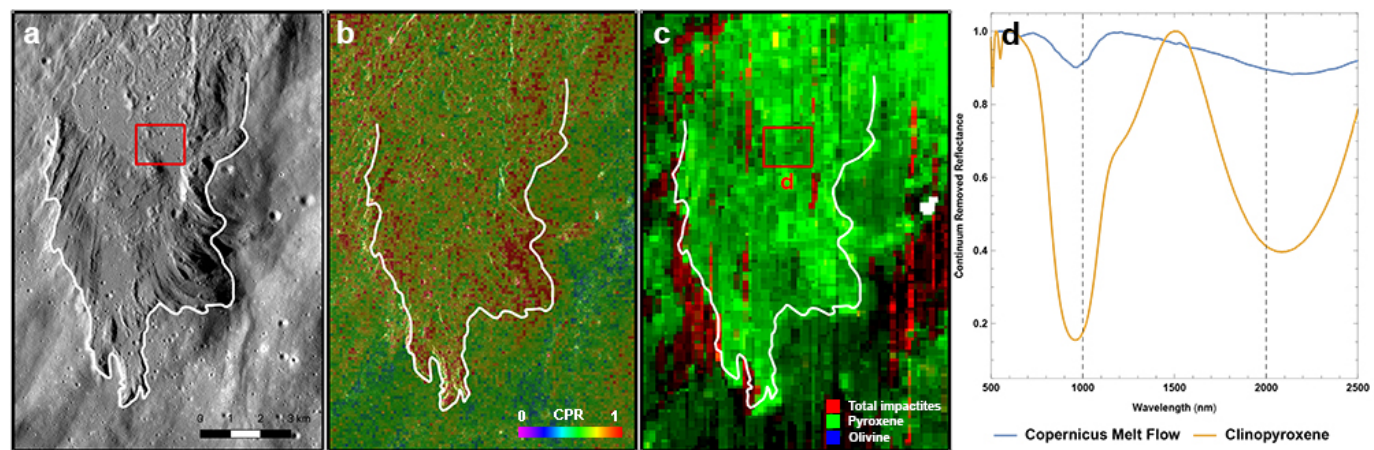

931 Figure 27: (a) LROC NAC image of a melt flow south of Copernicus crater 932 (M1111947720.IMG). (b) This portion of the ejecta has a high circular 933 polarization ratio (CPR) in an S-Band image acquired by Mini-RF 934 (LSZ_02991_1CD_XKU_00S340_V1.IMG), suggesting a surface that is rough at 935 the decimeter scale. (c) Spectral unmixing results of this region suggest the melt 936 flow is consistent with the pyroxene endmember (EM1). A red box indicates 937 where the spectrum shown in (d) was extracted. (d) Average continuum removed 938 spectrum of the melt flow, compared to the a clinopyroxene spectrum from Figure 9394 (sample DL-CMP-011). 


\section{4. Discussion}

943

944 In this work, we examined the spectral characteristics of impact melt

945 deposits around seven different lunar craters. We applied a spectral unmixing

946 model to the data to determine the most likely spectral endmember groupings for

947 the melt deposits around each crater. The four potential endmembers groups in

948 our model included pure crystalline pyroxenes (EM1), pure crystalline olivines

949 (EM2), fast-quenched synthetic lunar glasses (EM3), and impact melts and

950 breccias (both synthetic and natural) (EM4). In all cases, the impact melt-bearing

951 deposits were not consistent with the fast-quenched glass endmembers (EM3).

952 Most were consistent with the pyroxene endmember (EM1), and some were

953 consistent with the impact melts and breccia endmember (EM4). These latter

954 endmembers are represented by both the Apollo samples and slow-quenched

955 synthetic samples created for this work (see Table 1 and Figure 4). The partially

956 glassy endmembers in EM4 are spectrally dominated by quench crystallites of

957 pyroxene, but are distinct enough from pure crystalline pyroxene to be

958 distinguishable in some cases (see Section 4.2 below). A summary of the results is

959 presented in Table 3.

960 
961 Table 3: Summary of the results of the spectral unmixing model.

\begin{tabular}{|l|l|}
\hline Crater & Spectral Character of Melt Deposits in Model \\
\hline Donner M & (EM1) Pyroxene (melt flow) \\
\hline Tharp & $\begin{array}{l}\text { (EM4) Melts + Breccias (melt pond) } \\
\text { (EM1) Pyroxene (melt veneer) }\end{array}$ \\
\hline Giordano Bruno & $\begin{array}{l}\text { (EM1) Pyroxene (melt flow) } \\
\text { (EM2) Olivine (melt veneer) }\end{array}$ \\
\hline Aristarchus & None (melts not consistent with any end member) \\
\hline Glushko & (EM4) Melts + Breccias (melt flow) \\
\hline King & $\begin{array}{l}\text { None (Al-Tusi melt pond) } \\
\text { (EM1) Pyroxene (possible melt flow) }\end{array}$ \\
\hline Copernicus & (EM1) Pyroxene (interior and exterior melt flows) \\
\hline
\end{tabular}

$962{ }^{\mathrm{a}}$ Olivine signature likely a false positive.

963

964 4.1 Interpretations of the results

965

966 We seek to use these results to infer the cause of the unusual roughness

967 properties of lunar impact melt deposits. As previously mentioned, they appear

968 exceptionally rough/blocky at the decimeter scale, but smooth at the meter scale.

969 In Neish et al. [2017], we hypothesized that the melt flows may be similar to

970 "transitional" pahoehoe lava flows on Earth. In these flows, initially smooth

971 pahoehoe is mechanically fractured by later surges of lava to form "rubbly" or

972 "slabby" forms of pahoehoe. We examined several terrestrial lava flows of this

973 type in Hawai'i, Iceland, and Idaho and could find no analogues with similar

974 roughness properties. The closest analogue was a rubbly lava flow in Iceland, but

975 it only had moderate values of CPR when compared to the lunar melt deposits

$976(\sim 0.5$ vs. 1$)$. 
977 Another hypothesis that we considered in Neish et al. [2017] was that the

978 radar was sensing the disrupted surface of the melt flow, broken apart by impact

979 gardening and covered with regolith. An S-Band radar such as Mini-RF can sense

980 decimeter-sized blocks buried up to $\sim 1 \mathrm{~m}$ in lunar regolith. To test this

981 hypothesis, we compared the roughness properties of fresh impact melt deposits

982 to those of fresh lava flows on the Moon (specifically, Ina D). If they were formed

983 in the same way, impact gardening should affect them in a similar way. We found

984 that although the fresh lunar lava flows had similar roughness properties to the

985 fresh impact melt flow at the meter scale (similar RMS slope and Hurst

986 exponent), their radar properties were quite different. Ina D had low CPR values

987 at S-Band, similar to the surrounding regolith. This implies fresh lava flows and

988 fresh impact melt deposits are not emplaced in the same way on the Moon.

989 Indeed, there are several notable differences between the emplacement of

990 lava flows and impact melt deposits [Osinski et al., 2018]: (1) Impact melting

991 results in total melting, as opposed to partial melting of target rocks, (2) impact

992 melts may be superheated, while lava flows are erupted near the liquidus, and (3)

993 impact melts are clast-rich, while lava flows are not. With these differences in

994 mind, we investigate two new hypotheses to explain the surface texture of lunar

995 impact melt deposits in this work. In the first, we speculate that the entrainment of

996 clasts within the melt deposits might alter their surface texture. As discussed

997 above, melt deposits around Aristarchus crater and certain Martian craters adopt 
998 the spectral signature of the surrounding materials [Zanetti, 2015; Hopkins et al.,

999 2017]. This may suggest that the spectra are dominated by the presence of clasts

1000 in the melt. However, we deem it unlikely that clasts would increase the

1001 decimeter-scale roughness of the melt surface, without also altering its meter-

1002 scale roughness. For example, at Mistastin crater on Earth, observed clasts range

1003 in size from centimeter to meter scale [Grieve, 1975; Mader and Osinski, 2018].

1004 So if clasts were the cause of the increased decimeter-scale roughness, we would

1005 expect a similar increase in meter-scale roughness.

1006 In the second hypothesis, we suggest that the different cooling history

1007 experienced by lunar impact melt produces a glassier surface layer than that found

1008 in lunar lava flows. Although we find no spectral evidence of fast-quenched

1009 glasses in the melt deposits (similar to those found in pyroclastic deposits), we do

1010 find spectra that are consistent with the slow-cooled synthetic melts and/or

1011 returned samples of impact melt breccias from the Moon. In this scenario, a

1012 surficial layer may form on the melt deposits that contains both glass and fine-

1013 grained crystals of minerals including pyroxene, olivine, and plagioclase. As we

1014 discussed previously, a sample with more than $60 \%$ glass is necessary for the

1015 presence of glass to be obvious in a mixed spectrum with pyroxene [Tompkins

1016 and Pieters, 2010]. Conversely, pyroxene is spectrally dominant at just 2 vol. \%

1017 abundance in pyroxene-plagioclase mixtures [Cheek and Pieters, 2014]. This

1018 glassy surficial layer would lie on top of a more crystalline subsurface deposit, 
1019 which experienced a slower cooling rate. If this surface layer is later disrupted

1020 through impact gardening or explosive degassing of vesicles, it may form a

1021 blocky layer over a melt flow that remains smooth at the meter scale (Figure 28).

1022

1034 than crystalline lunar rocks, and thus, is more likely to be disrupted to form flat

1035 cleavage surfaces that can act as corner reflectors (see Figure 2). Scattering from 1036 natural corner reflectors increases the circular polarization ratio of the signal 
1037 [Campbell et al., 2012] to the values observed by Arecibo and Mini-RF of the 1038 melt deposits [Campbell et al., 2010; Neish et al., 2017].

1039 There is evidence in the Apollo collection that supports this hypothesis, 1040 including rare examples of glassy impact melt rocks [Osinski et al., 2018]. For 1041 example, sample 64455 from the Apollo 16 collection is a $5 \mathrm{~cm}$ long egg-shaped 1042 object almost completely covered with black glass up to a $\mathrm{cm}$ in thickness, with 1043 small vesicles concentrated along the basalt/glass contact [Ryder and Norman, 1044 1980; Figure 29]. Most of these glassy impact melt rocks are not completely 1045 composed of glass, but also show evidence of micron-sized microlites, commonly 1046 clinopyroxene and plagioclase. This is consistent with our spectral analyses of 1047 lunar impact melt deposits. Still, one may wonder why such samples are so rare, 1048 given the large amount of impact melt present on the lunar surface [e.g., Campbell 1049 et al., 2018]. It is possible that these samples are not more common because they 1050 are so easily broken down by impact gardening. For example, the impact melt 1051 flow at Korolev Z (Figure 1) has a lower rock abundance in the Diviner data than 1052 other portions of its ejecta blanket [Neish et al., 2017]. Bandfield et al. [2011] 1053 suggested that the low rock abundance observed over many lunar impact melt 1054 deposits implies that these deposits have mechanical properties that result in a 1055 more rapid development of regolith cover. Any glass present may be quickly 1056 processed into a fine particulate layer overlying a buried layer of decimeter sized 1057 blocks. 


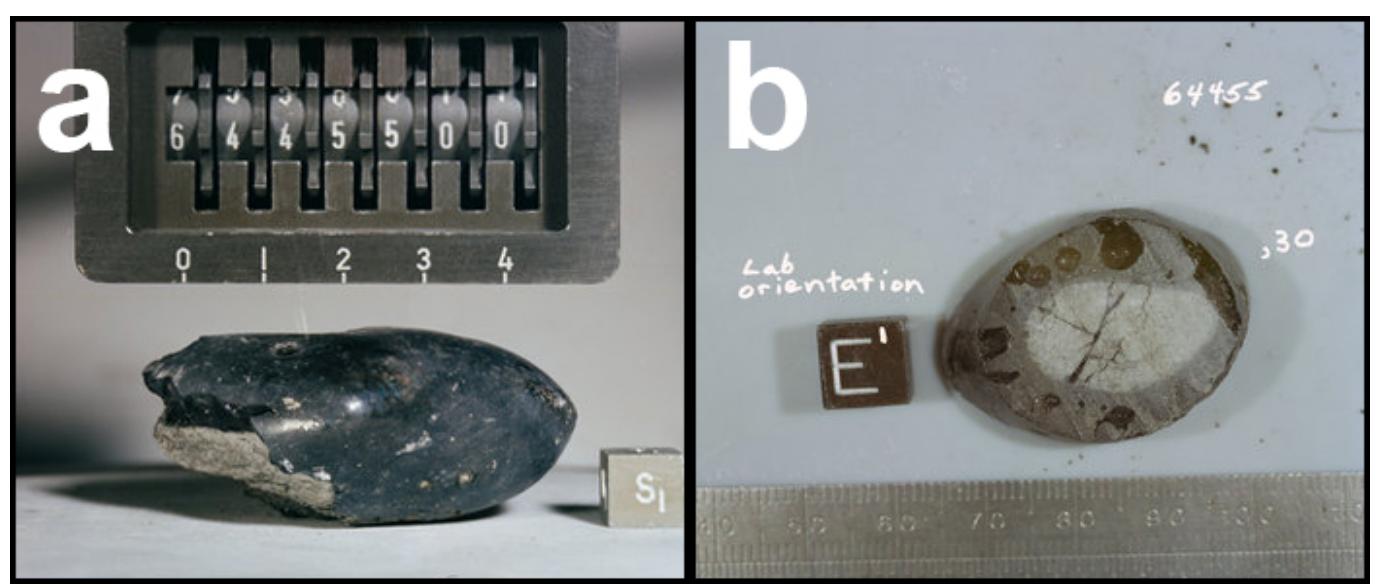

1060 Figure 29: (a) Photograph of Apollo 16 sample 64455,0, with a $1 \mathrm{~cm}$ scale cube 1061 at lower right (photo number S72-43254B). This sample is almost entirely 1062 covered in black glass. (b) Photograph of Apollo 16 sample 64455,30, with ruler 1063 for scale. This photograph shows the interior structure of the sample, 1064 demonstrating a glass thickness of up to $\sim 1 \mathrm{~cm}$ (photo number S91-36325).

1067 4.2 Limitations to the technique

1069 There are some limitations to the spectral unmixing model used in this

1070 work that bear discussion. For example, if a spectral feature is ubiquitous and part

1071 of the "background" of the entire scene, then the model may not pick it out as

1072 being distinct because it uses spectra from the scene itself as an endmember.

1073 Thus, any impact melt deposits that have spectral properties similar to the

1074 background may not show a preferred endmember. Some of the melts identified at

1075 Aristarchus or the Al-Tusi melt pond at King may fall into this category. In 
1076 addition, any regions that are spectrally bland, with broad but weak one and two

1077 micron bands, are difficult to confidently assign to an endmember. Thus in some

1078 cases, there are likely false positive results (such as the "olivine" detection at

1079 Giordano Bruno) where the spectral model attempted to assign an endmember to a

1080 region that does not show distinct spectral features. Given the lack of spectral

1081 features in these regions, it is difficult to confidently identify what species may be

1082 present, but glass, plagioclase, or spectral mixtures are a few possibilities.

1083 We also see differences in the model outputs when we include additional

1084 endmembers. For example, we get different results when we fit the data to three

1085 endmembers (EM1, EM2, and EM3) instead of four (Figure 30). We can see that

1086 with only three end members, the region southwest of Aristarchus is not fit by any

1087 of the endmembers, but when we include the fourth endmember, the model finds

1088 a fit to the melts plus breccias end member (EM4). The fact that the new

1089 endmember is fit is a unique indication that something distinct is present, because

1090 an F-test is used in the inverse model. If the new endmember didn't improve the

1091 model fit with statistical significance, it would not be modeled. Thus, it is

1092 important to utilize all reasonable endmembers when utilizing this model in order

1093 to best constrain the composition of the lunar surface. 


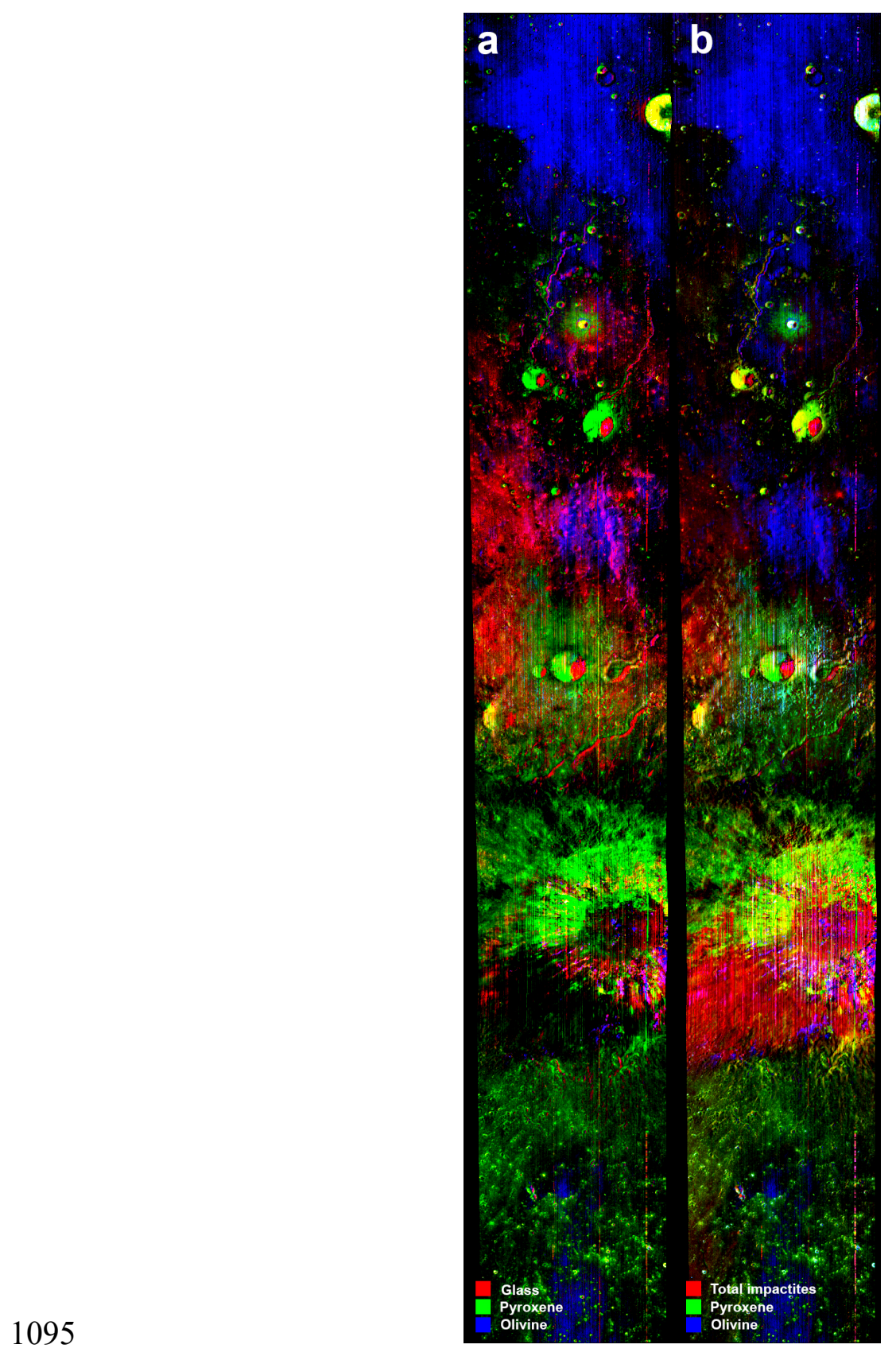

1096 Figure 30: A comparison of the model results from a fit of 1097 M3G20090209T072710_V01_RFL.IMG with (a) three end-members (glass, 1098 pyroxene, and olivine) and (b) four end-members (glass, pyroxene, olivine, and 1099 melts plus breccias). In (b), glass (EM3) and melts plus breccias (EM4) have been 1100 combined into "total impactites". 
1101 The resolution of the images may also play a role in the results of our 1102 model. Between optical period 2A and 2B, the orbit of the Chandrayaan-1 1103 spacecraft was increased, which reduced the resolution of the images by a factor

1104 of two. Roughly half of our images are from the lower resolution optical periods.

1105 To determine if this has affected our results, we compared the model outputs from 1106 two images acquired from the same region of Glushko crater (Figure 31). The

1107 model fits from the two different resolutions are similar, although there are a few

1108 regions where they differ (e.g., the ejecta north of the crater). We judge that the

1109 blue streaks on the northern rim of Glushko in the lower resolution image are

1110 likely the result of noise rather than a true glass signature, since they are not

1111 observed in the higher-resolution $\mathrm{M}^{3}$ image. However, the melt flow of interest is

1112 fit to the melts and breccias end member (EM4) in both images, giving us

1113 confidence in the results in the region of interest.

1114

1115 


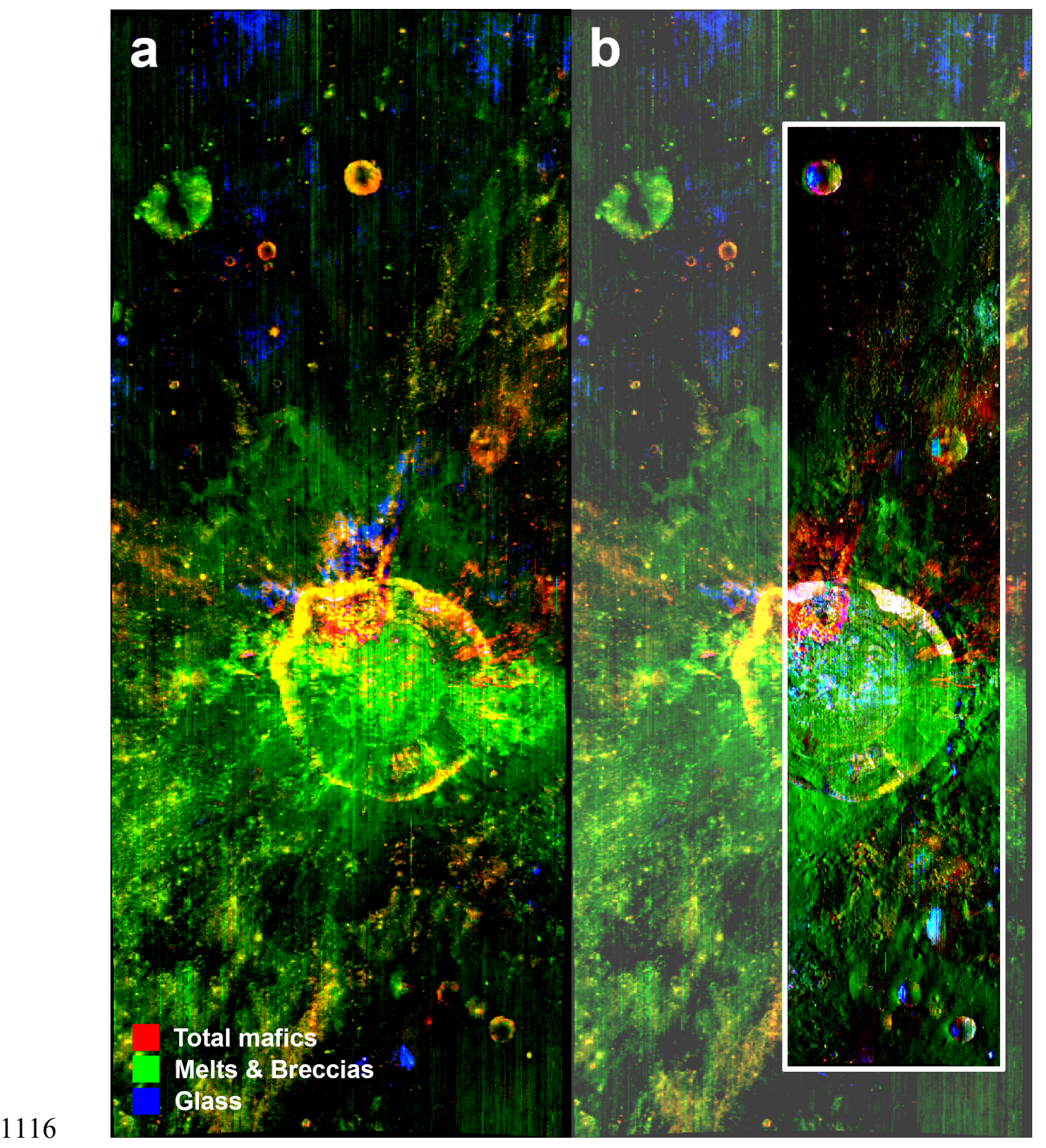

1117 Figure 31: $\mathrm{M}^{3}$ images of Glushko crater taken during (a) optical period 2C 1118 (M3G20090614T131003_V01_RFL.IMG; $280 \mathrm{~m} / \mathrm{pixel}$ ) and (b) optical period 2A 1119 (M3G20090614T131003_V01_RFL.IMG; $140 \mathrm{~m} / \mathrm{pixel}$ ). In (b), the higher 1120 resolution image is overlain on the lower resolution image of the same region. 1121 Both images are scaled linearly from 0.01 to their maximum value, to remove 1122 spuriously low values. 
1123 Finally, we note that our sample size was limited to only seven craters,

1124 and could be expanded to include more of the impact-melt bearing craters

1125 identified by Neish et al. [2014]. (However, some craters closer to the poles have

1126 lighting issues that would make this analysis difficult.) It would be particularly

1127 interesting to compare the results of highlands melt deposits versus those in the

1128 mare. For example, a recent study by Morrison et al. [2019] studied the

1129 crystallization of melted highlands and mare simulants. They found that highlands

1130 simulants have a higher melting point than mare simulants $\left(\sim 1325^{\circ} \mathrm{C}\right.$ for mare-

1131 like basaltic JSC-1a vs. $>1450^{\circ} \mathrm{C}$ for highlands-like norite and anorthite). They

1132 also demonstrated that anorthite and norite samples crystallize over a very narrow

1133 temperature interval after crossing the liquidus, whereas basaltic samples

1134 experience a more moderate amount of crystallization before experiencing a rapid

1135 increase after $\sim 125^{\circ} \mathrm{C}$ of undercooling. Thus, if melts are quenched at a given

1136 temperature during cooling, a highlands melt deposit may contain more

1137 crystalline material than a mare melt deposit.

1138

1139 5. Conclusions

1140

1141 We examined the spectral characteristics of seven impact melt bearing

1142 craters on the Moon. We utilized a spectral unmixing model to look for evidence

1143 of one of four endmember groups in the melt deposits: pyroxenes, olivines, fast- 
1144 quenched lunar glass simulants, and impact melts and breccias (both synthetic and

1145 natural). We found that the majority of the melt deposits were spectrally

1146 dominated by pyroxene, consistent with the pyroxene and/or impact melts plus

1147 breccia endmembers. This suggests that the melt deposits are either crystalline

1148 deposits of pyroxene-rich rocks, a mixture of impact melt and pyroxene-rich lithic

1149 clasts, or a glassy material that contains pyroxene minerals in the form of quench

1150 crystallites. The latter interpretation is most consistent with the Mini-RF

1151 observations, which show extremely high decimeter-scale roughness. This

1152 roughness could be the result of a glassy surficial layer shattering during impact

1153 gardening to produce decimeter scale blocks over a deposit that remains smooth at

1154 the meter scale. This suggests that impact melt deposits on the Moon likely

1155 experience different cooling conditions compared to lunar lava flows, given their

1156 unique melting and emplacement conditions.

1157

1158 


\section{Acknowledgments}

1160

1161 We thank the LRO and Chandrayaan-1 projects for their efforts in returning the

1162 data presented here. We also thank R. Wysocki and J. Karson of the Syracuse

1163 Lava Project for hosting us at their facility in October 2017, a visit which

1164 ultimately inspired this work. Finally, we thank J. Molaro for helpful

1165 conversations about rock failure, and B. Horgan, M. McBride, S. Besse, and an

1166 anonymous reviewer for suggestions that significantly improved the manuscript.

1167 C.N. and M.Z. were supported by an NSERC Discovery grant. 


\section{References}

1169

1170 Altindag, R. (2010). Reply to the discussion by Yagiz on "Assessment of some

1171 brittleness indexes in rock-drilling efficiency”. Rock Mechanics and Rock

1172 Engineering, 43, 375-376.

1173

1174 Ashley, J. W., Robinson, M. S., Hawke, B. R., van der Bogert, C. H., Hiesinger, 1175 H., Sato, H., Speyerer, E. J., Enns, A. C., Wagner, R. V., Young, K. E., Burns, K.

1176 N. (2012). Geology of the King crater region: New insights into impact melt

1177 dynamics on the Moon. Journal of Geophysical Research, 117, E00H29, 1178 doi:10.1029/2011JE003990.

1179

1180 Ashworth, D. G. (1978). Lunar and planetary impact erosion. In: J.A.M.

1181 McDonnell (Ed.), Cosmic Dust. John Wiley, Hoboken, NJ, pp. 427-526

1182

1183 Bandfield, J. L., Ghent, R. R., Vasavada, A. R., Paige, D. A., Lawrence, S. J., 1184 Robinson, M. S. (2011). Lunar surface rock abundance and regolith fines 1185 temperatures derived from LRO Diviner Radiometer data. Journal of Geophysical 1186 Research, 116, E00H02, doi:10.1029/2011JE003866. 
1188 Besse, S., Sunshine, J.M., Staid, M.I., Petro, N.E., Boardman, J.W., Green, R.O.,

1189 Head, J.W., Isaacson, P.J., Mustard, J.F. and Pieters, C.M. (2011). Compositional

1190 variability of the Marius Hills volcanic complex from the Moon Mineralogy

1191 Mapper (M3). Journal of Geophysical Research: Planets, 116(E6).

1192

1193 Besse, S., Sunshine, J., Staid, M., Boardman, J., Pieters, C., Guasqui, P., Malaret,

1194 E., McLaughlin, S., Yokota, Y., Li, J.Y. (2013). A visible and near-infrared

1195 photometric correction for Moon Mineralogy Mapper (M3). Icarus, 222, 229-242.

1196

1197 Besse, S., Sunshine, J. M., Gaddis, L. R. (2014). Volcanic glass signatures in 1198 spectroscopic survey of newly proposed lunar pyroclastic deposits. Journal of 1199 Geophysical Research: Planets, 119, 355-372.

1200

1201 Bhiravarasu, S. Bhattacharya, S. Chauhan, P. (2017). Giordano Bruno crater on 1202 the Moon: Detection and Mapping of Hydration Features of Endogenic and/or 1203 Exogenic Nature. AAS Division for Planetary Sciences Meeting Abstracts, 49, 1204404.05.

1206 Bray, V. J., Tornabene, L. L., Keszthelyi, L. P., McEwen, A. S., Hawke, B. R., 1207 Giguere, T. A., Kattenhorn, S. A., Garry, W. B., Rizk, B., Caudill, C. M., Gaddis, 1208 L. R., and van der Bogert, C. H. (2010). New insight into lunar impact melt 
1209 mobility from the LRO camera. Geophysical Research Letters, 37, L21202, 1210 doi:10.1029/2010GL044666.

1211

1212 Campbell, B. A., Carter, L. M., Hawke, B. R., Campbell, D. B., Ghent, R. R. 1213 (2008). Volcanic and impact deposits of the Moon's Aristarchus Plateau: A new 1214 view from Earth-based radar images. Geology, 36, 135-138, 1215 doi:10.1130/G24310A.

1216

1217 Campbell, B. A., Hawke, B. R., Carter, L. M., Ghent, R. R., Campbell, D. B. 1218 (2009). Rugged lava flows on the Moon revealed by Earth-based radar. 1219 Geophysical Research Letters, 36(22).

1220

1221 Campbell, B. A., Carter, L. M., Campbell, D. B., Nolan, M., Chandler, J., Ghent, 1222 R. R., Hawke, B. R., Anderson, R. F., Wells, K. (2010). Earth-based 12.6-cm 1223 wavelength radar mapping of the Moon: New views of impact melt distribution 1224 and mare physical properties. Icarus, 208, 565-573, 1225 doi:10.1016/j.icarus.2010.03.011.

1226 
1227 Campbell, B. A. (2012). High circular polarization ratios in radar scattering from 1228 geologic targets. Journal of Geophysical Research, 117, E06008, 1229 doi:10.1029/2012JE004061

1230

1231 Campbell, B. A., Weitz, C. M., Whitten, J. L., Morgan, G. A. (2018). Evidence

1232 for impact melt sheets in lunar highland smooth plains and implications for polar 1233 landing sites. Icarus, 314, 294-298.

1234

1235 Cannon, K. M., Mustard, J. F. (2015). Preserved glass-rich impactites on Mars. 1236 Geology, 43, 635-638, doi:10.1130/G36953.1.

1238 Cannon, K. M., Mustard, J. F., Parman, S. W., Sklute, E. C., Dyar, M. D., Cooper, 1239 R. F. (2017). Spectral properties of Martian and other planetary glasses and their 1240 detection in remotely sensed data. Journal of Geophysical Research-Planets, 122, 1241 249-268, doi:10.1002/2016JE005219.

1243 Carter, L. M., Campbell, B. A., Hawke, B. R., Campbell, D. B., Nolan, M. C.

1244 (2009). Radar remote sensing of pyroclastic deposits in the southern Mare

1245 Serenitatis and Mare Vaporum regions of the Moon. Journal of Geophysical 1246 Research: Planets, 114(E11). 
1248 Carter, L. M., Neish, C. D., Bussey, D. B. J., Spudis, P. D., Patterson, G. W.,

1249 Cahill, J. T., Raney, R. K. (2012). Initial observations of lunar impact melts and

1250 ejecta flows with the Mini-RF radar. Journal of Geophysical Research, 117,

1251 E00H09, doi:10.1029/2011JE003911.

1252

1253 Carter, L. M., Campbell, B. A., Neish, C. D., Nolan, M. C., Patterson, G. W.,

1254 Jensen, J. R., Bussey, D. B. J. (2017). A Comparison of Radar Polarimetry Data

1255 of the Moon From the LRO Mini-RF Instrument and Earth-Based Systems. IEEE

1256 Transactions on Geoscience and Remote Sensing, 55, 1915-1927,

1257 doi:10.1109/TGRS.2016.2631144.

1258

1259 Cheek, L. C., Pieters, C. M. (2014). Reflectance spectroscopy of plagioclase-

1260 dominated mineral mixtures: Implications for characterizing lunar anorthosites

1261 remotely. American Mineralogist, 99, 1871-1892, doi:10.2138/am-2014-4785.

1262

1263 Clark, R. N., Pieters, C. M., Green, R. O., Boardman, J. W., Petro, N. E. (2011).

1264 Thermal removal from near-infrared imaging spectroscopy data of the Moon.

1265 Journal of Geophysical Research: Planets, 116(E6).

1266 
1267 Daubar, I. J., Kring, D. A., Swindle, T. D., Jull, A. J. T. (2002). Northwest Africa 1268 482: A crystalline impact-melt breccia from the lunar highlands. Meteoritics \& 1269 Planetary Science, 37, 1797-1813, doi:10.1111/j.1945-5100.2002.tb01164.x.

1271 Denevi, B. W., Koeber, S. D., Robinson, M. S., Garry, W. B., Hawke, B. R., Tran, 1272 T. N., Lawrence, S. J., Keszthelyi, L. P., Barnouin, O. S., Ernst, C. M., 1273 Tornabene, L. L. (2012). Physical constraints on impact melt properties from 1274 Lunar Reconnaissance Orbiter Camera images. Icarus, 219, 665-675, 1275 doi:10.1016/j.icarus.2012.03.020.

1277 Dhingra, D., Pieters, C. M., Head, J. W., Isaacson, P. J. (2013). Large 1278 mineralogically distinct impact melt feature at Copernicus crater - Evidence for 1279 retention of compositional heterogeneity. Geophysical Research Letters, 10, 1-6, 1280 doi:10.1002/grl.50255.

1281

1282 Dong, C., Carter, L. M. (2014). Analysis and comparison of physical properties 1283 and morphology of impact melt flows on Venus and the Moon. American 1284 Geophysical Union, Fall Meeting 2014, Abstract P21B-3914.

1285 
1286 Flemming, R.L. (2007) Micro X-ray diffraction ( $\mu$ XRD): a versatile technique for 1287 characterization of Earth and planetary materials. Canadian Journal of Earth 1288 Sciences, 44, 1333-1346, doi:10.1139/E07-020.

1290 French, Bevan M. (1998) Traces of catastrophe: A handbook of shock1291 metamorphic effects in terrestrial meteorite impact structures. Lunar and 1292 Planetary Institute.

1294 Fullagar, R., Torrence, R. (1991). Obsidian exploitation at Umleang, Lou Island. 1295 Report of the Lapita Homeland Project, 20, 113-43.

1297 Gaddis, L. R., Pieters, C. M., Hawke, B. R. (1985). Remote sensing of lunar 1298 pyroclastic mantling deposits. Icarus, 61, 461-489, doi:10.1016/0019$1299 \quad 1035(85) 90136-8$.

1301 Glotch, T. D., Lucey, P. G., Bandfield, J. L., Greenhagen, B. T., Thomas, I. R., 1302 Elphic, R. C., Bowles, N., Wyatt, M. B., Allen, C. C., Donaldson Hanna, K., 1303 Paige, D. A. (2010). Highly Silicic Compositions on the Moon. Science, 329, 1304 1510-1513, doi:10.1126/science.1192148. 
1306 Green, R. O., and 53 colleagues (2011). The Moon Mineralogy Mapper (M3)

1307 imaging spectrometer for lunar science: Instrument description, calibration, on-

1308 orbit measurements, science data calibration and on-orbit validation. Journal of

1309 Geophysical Research, 116, doi:10.1029/2011JE003797.

1310

1311 Grieve, R. A. (1975). Petrology and chemistry of the impact melt at Mistastin

1312 Lake crater, Labrador. Geological Society of America Bulletin, 86, 1617-1629.

1313

1314 Harmon, J. K., Nolan, M. C., Husmann, D. I., Campbell, B. A. (2012). Arecibo

1315 radar imagery of Mars: The major volcanic provinces. Icarus, 220, 990-1030,

1316 doi:10.1016/j.icarus.2012.06.030.

1317

1318 Hawke, B.R., Head, J.W. (1977). Impact melt in lunar crater interiors. In: D.J.

1319 Roddy, R.O. Pepin, and R.B. Merrill (Eds.), Impact and explosion cratering.

1320 Pergamon Press, New York, NY, pp. 815.

1321

1322 Heather, D. J., Dunkin, S. K. (2003). Geology and stratigraphy of King crater,

1323 lunar farside. Icarus, 163, 307-329, doi:10.1016/S0019-1035(02)00063-5.

1324

1325 Hill, R. J., Tsambourakis, G., Madsen, I. C. (1993). Improved petrological modal 1326 analyses from X-ray powder diffraction data by use of the Rietveld method I. 
1327 Selected igneous, volcanic, and metamorphic rocks. Journal of Petrology, 34, $1328 \quad 867-900$.

1329

1330 Hopkins, R. T., Tornabene, L. L., Osinski, G. R. (2017). The central uplift of

1331 Elorza Crater: Insights into its geology and possible relationships to the Valles

1332 Marineris and Tharsis regions. Icarus, 284, 284-304.

1333

1334 Horgan, B. H. N., Cloutis, E. A., Mann, P., Bell, J. F. (2014). Near-infrared

1335 spectra of ferrous mineral mixtures and methods for their identification in 1336 planetary surface spectra. Icarus, 234, 132-154, doi:10.1016/j.icarus.2014.02.031.

1338 Howard, K.A., Wilshire, H.G. (1975). Flows of impact melt at lunar craters.

1339 Journal of Research of the U.S. Geological Survey, 3, 237.

1341 Hui, H., Hess, K.-U., Zhang, Y., Nichols, A. R. L., Peslier, A. H., Lange, R. A.,

1342 Dingwell, D. B., Neal, C. R. (2018) Cooling rates of lunar orange glass beads.

1343 Earth and Planetary Science Letters, 503, 88-94.

1345 Isaacson, P. J., Pieters, C. M., Besse, S., Clark, R. N., Head, J. W., Klima, R. L.,

1346 Mustard, J. F., Petro, N. E., Staid, M. I., Sunshine, J. M., Taylor, L. A., Thaisen,

1347 K. G., Tompkins, S. (2011). Remote compositional analysis of lunar olivine-rich 
1348 lithologies with Moon Mineralogy Mapper (M3) spectra. Journal of Geophysical

1349 Research, 116, E00G11, doi:10.1029/2010JE003731.

1350

1351 Kahraman, S., Toraman, O. Y., Cayirli, S. (2018). Predicting the strength and

1352 brittleness of rocks from a crushability index. Bulletin of Engineering geology and

1353 the Environment, 77, 1639-1645.

1354

1355 Karson, J. A., Wysocki, R. (2012). Do-it-yourself lava flows: Science, art and 1356 education in the Syracuse University LavaProject. Earth, 57, 38-41.

1357

1358 Keszthelyi, L., Denlinger, R. (1996). The initial cooling of pahoehoe flow lobes,

1359 Bulletin of Volcanology, 58, 5-18, doi:10.1007/s004450050121.

1360

1361 Klima, R. L., Dyar, M. D., Pieters, C. M. (2011). Near-infrared spectra of

1362 clinopyroxenes: Effects of calcium content and crystal structure. Meteoritics \&

1363 Planetary Science, 46, 379-395, doi:10.1111/j.1945-5100.2010.01158.x.

1364

1365 Klug, H.P., Alexander, L.E. (1962). X-ray diffraction procedures, 3rd Edition.

1366 Wiley, New York, NY, pp. 716.

1367 
1368 McEwen, A. S., Robinson, M. S., Eliason, E. M., Lucey, P. G., Duxbury, T. C.,

1369 Spudis, P. D. (1994). Clementine observations of the Aristarchus region of the

1370 Moon. Science, 266, 1858-1862, doi:10.1126/science.266.5192.1858.

1371

1372 Mader, M. M., Osinski, G. R. (2018). Impactites of the Mistastin Lake impact

1373 structure: Insights into impact ejecta emplacement. Meteoritics \& Planetary

1374 Science, 53, 2492-2518.

1375

1376 Morota, T., Haruyama, J., Miyamoto, H., Honda, C., Ohtake, M., Yokota, Y.,

1377 Matsunaga, T., Hirata, N., Demura, H., Takeda, H., Ogawa, Y., Kimura, J. (2009).

1378 Formation age of the lunar crater Giordano Bruno. Meteoritics \& Planetary

1379 Science, 44, 1115-1120, doi:10.1111/j.1945-5100.2009.tb01211.x.

1380

1381 Morrison, A. A., Zanetti, M., Hamilton, C. W., Lev, E., Neish, C. D., Whittington, 1382 A. G. (2019). Rheological investigation of lunar highland and mare impact melt 1383 simulants. Icarus, 317, 307-323, doi:10.1016/j.icarus.2018.08.001.

1385 Mustard, J. F., Pieters, C. M., Isaacson, P. J., Head, J. W., Besse, S., Clark, R. N., 1386 Klima, R. L., Petro, N. E., Staid, M. I., Sunshine, J. M., Runyon, C. J., Tompkins, 1387 S. (2011). Compositional diversity and geologic insights of the Aristarchus crater 
1388 from Moon Mineralogy Mapper data. Journal of Geophysical Research, 116(E6),

1389 E00G12, doi:10.1029/2010JE003726.

1390

1391 Neish, C. D., Blewett, D. T., Bussey, D. B. J., Lawrence, S. J., Mechtley, M.,

1392 Thomson, B. J. (2011). The surficial nature of lunar swirls as revealed by the 1393 Mini-RF instrument. Icarus, 215, 186-196.

1395 Neish, C. D., Blewett, D. T., Harmon, J. K., Coman, E. I., Cahill, J. T. S., Ernst,

1396 C. M. (2013). A comparison of rayed craters on the Moon and Mercury. Journal 1397 of Geophysical Research-Planets, 118, 2247-2261, doi:10.1002/jgre.20166.

1399 Neish, C. D., Carter, L. M. (2014). Planetary radar. In Encyclopedia of the Solar 1400 System (pp. 1133-1159). Elsevier.

1401

1402

1403 Neish, C. D., Madden, J., Carter, L. M., Hawke, B. R., Giguere, T., Bray, V. J., 1404 Osinski, G. R., Cahill, J. T. S. (2014). Global distribution of lunar impact melt 1405 flows, Icarus, 239, 105-117, doi:10.1016/j.icarus.2014.05.049.

1406

1407 Neish, C. D., Hamilton, C. W., Hughes, S. S., Nawotniak, S. K., Garry, W. B., 1408 Skok, J. R., Elphic, R. C., Schaefer, E., Carter, L. M., Bandfield, J. L., Osinski, G. 
1409 R., Lim, D., Heldmann, J. L. (2017). Terrestrial analogues for lunar impact melt

1410 flows. Icarus, 281, 73-89, doi:10.1016/j.icarus.2016.08.008.

1411

1412 Nozette, S., Spudis, P., Bussey, B., Jensen, R., Raney, K., Winters, H.,

1413 Lichtenberg, C.L., Marinelli, W., Crusan, J., Gates, M., and Robinson, M. (2010).

1414 The Lunar Reconnaissance Orbiter Miniature Radio Frequency (Mini-RF)

1415 Technology Demonstration, Space Science Reviews, 150, 285-302,

1416 doi:10.1007/s11214-009-9607-5.

1417

1418 Osinski, G. R., Tornabene, L. L., Grieve, R. A. F. (2011). Impact ejecta

1419 emplacement on terrestrial planets, Earth and Planetary Science Letters, 310,

$1420 \quad 167-181$, doi:10.1016/j.eps1.2011.08.012.

1421

1422 Osinski, G. R., Grieve, R. A. F., Bleacher, J. E., Neish, C. D., Pilles, E. A., 1423 Tornabene, L. L. (2018). Igneous rocks formed by hypervelocity impact. Journal 1424 of Volcanology and Geothermal Research, 353, 25-54, 1425 doi:10.1016/j.jvolgeores.2018.01.015.

1426

1427 Pieters, C. M. (1983). Strength of mineral absorption features in the transmitted 1428 component of near-infrared reflected light: First results from RELAB. Journal of 1429 Geophysical Research: Solid Earth, 88, 9534-9544. 
1431 Pieters, C., and 19 colleagues (2009). The Moon Mineralogy Mapper ( $\left.\mathrm{M}^{3}\right)$ on

1432 Chandrayaan-1. Current Science,96, 500-505.

1433

1434 Plescia, J. B., Robinson, M. S., Paige, D. A. (2010). Giordano Bruno: The Young 1435 and the Restless. Lunar and Planetary Institute Science Conference Abstracts, 41, 14362038.

1437

1438 Robinson, M.S., and 22 colleagues (2010). Lunar Reconnaissance Orbiter Camera 1439 (LROC) instrument overview, Space Science Reviews, 150, 81-124, 1440 doi:10.1007/s11214-010-9634-2.

1441

1442 Ryder, G., Norman, M. D. (1980). Catalog of Apollo 16 Rocks, NASA Curatorial 1443 Branch Publication 52. NASA/Johnson Space Center, Houston.

1444

1445 Simonds, C.H., Warner, J.L., Phinney, W.C. (1976). Thermal regimes in cratered 1446 terrain with emphasis on the role of impact melt, American Mineralogist, 61, 1447 569-577.

1448 
1449 Smrekar, S., Pieters, C. M. (1985). Near-infrared spectroscopy of probable impact 1450 melt from three large lunar highland craters, Icarus, 63, 442-452, 1451 doi:10.1016/0019-1035(85)90056-9.

1453 Stopar, J. D., Hawke, B. R., Robinson, M. S., Denevi, B. W., Giguere, T. A.,

1454 Koeber, S. D. (2014). Occurrence and mechanisms of impact melt emplacement 1455 at small lunar craters, Icarus, 243, 337-357, doi:10.1016/j.icarus.2014.08.011.

1457 Sutton, S. R., Karner, J., Papike, J., Delaney, J. S., Shearer, C., Newville, M., 1458 Eng, P., Rivers, M., Dyar, M. D. (2005). Vanadium K edge XANES of synthetic 1459 and natural basaltic glasses and application to microscale oxygen barometry. 1460 Geochimica Et Cosmochimica Acta, 69, 2333-2348, 1461 doi:10.1016/j.gca.2004.10.013.

1463 Taylor, R. S., McLennan, S. (2009). Planetary crusts: Their composition, origin 1464 and evolution. Cambridge University Press, Cambridge, UK, pp. 378.

1466 Timms, N.E., Erickson, T.M., Pearce, M.A., Cavosie, A.J., Schmieder, M., 1467 Tohver, E., Reddy, S.M., Zanetti, M.R., Nemchin, A.A., Wittmann, A. (2017). A 1468 pressure-temperature phase diagram for zircon at extreme conditions. Earth1469 Science Reviews, 165, 185-202. 
1471 Tompkins, S., Pieters, C. M. (2010). Spectral characteristics of lunar impact melts 1472 and inferred mineralogy. Meteoritics \& Planetary Science, 45, 1152-1169, 1473 doi:10.1111/j.1945-5100.2010.01074.x.

1474

1475 Vaughan, W. M., Head, J. W., Wilson, L., Hess, P. C. (2013). Geology and 1476 petrology of enormous volumes of impact melt on the Moon: A case study of the 1477 Orientale basin impact melt sea. Icarus, 223, 749-765, 1478 doi:10.1016/j.icarus.2013.01.017.

1480 Wānke, H., Palme, H., Baddenhausen H., Dreibus, G., Jagoutz, E., Kruse, H., 1481 Palme, C., Spettel, B., Teschke, F., Thacker, R. (1975) New data on the chemistry 1482 of lunar samples: Primary matter in the lunar highlands and the bulk composition 1483 of the moon. Proc. Lunar Sci. Conf., 6, 1313-1340.

1484

1485 Yamamoto, S., Nakamura, R., Matsunaga, T., Ogawa, Y., Ishihara, Y., Morota, 1486 T., Hirata, N., Ohtake, M., Hiroi, T., Yokota, Y., Haruyama, J. (2010). Possible 1487 mantle origin of olivine around lunar impact basins detected by SELENE. Nature 1488 Geoscience, 3, 533, doi:10.1038/ngeo897. 
1490 Zanetti, M., Hiesinger, H., van der Bogert, C. H., Jolliff, B. L. (2011).

1491 Observation of Stratified Ejecta Blocks at Aristarchus Crater. Lunar and 1492 Planetary Science Conference, 42, 2262.

1493

1494 Zanetti, M. R. (2015). Investigating the Complexity of Impact Crater Ejecta. Arts

$1495 \&$ Sciences Electronic Theses and Dissertations, Washington University in St.

1496 Louis, 694.

1497

1498 Zhang, J., Jolliff, B. L. (2008). Aristarchus Region: A Potential Location for

1499 Future Surface Exploration. Lunar and Planetary Institute Science Conference 1500 Abstracts, 34, 2534.

1501

1502 Zisk, S. H., Hodges, C. A., Moore, H. J., Shorthill, R. W., Thompson, T. W., 1503 Whitaker, E. A., Wilhelms, D. E. (1977). The Aristarchus-Harbinger region of the 1504 moon: Surface geology and history from recent remote-sensing observations. The 1505 Moon, 17, 59-99, doi:10.1007/BF00566853. 